\title{
PERSISTENCE AMONG ADULT BASIC EDUCATION STUDENTS IN PRE-GED CLASSES
}

\author{
by
}

\section{John P. Comings, Andrea Parrella, and Lisa Soricone Harvard Graduate School of Education}

\section{NCSALL Reports \#12 \\ December 1999}

\author{
The National Center for the Study of Adult Learning and Literacy \\ Harvard Graduate School of Education \\ 101 Nichols House, Appian Way \\ Cambridge, MA 02138
}

\begin{abstract}
The work reported herein is supported by a subcontract from Harvard University under the Educational Research and Development Centers Program, Award Number R309B960002, as administered by the Office of Educational Research and Improvement/National Institute on Postsecondary Education, Libraries, and Lifelong Learning, U.S. Department of Education. However, the contents do not necessarily represent the positions or policies of NCSALL; World Education; the National Institute on Postsecondary Education, Libraries, and Lifelong Learning; the Office of Educational Research and Improvement; or the U.S. Department of Education, and you should not assume endorsement by the Federal Government.
\end{abstract}




\section{TABLE OF CONTENTS}

Acknowledgments

Executive Summary 3

Introduction $\quad \mathbf{1 1}$

$\begin{array}{lr}\text { Persistence } & 13\end{array}$

Literature Review

Theoretical Framework $\quad 26$

Methodology

Findings $\quad 35$

Description of the Sample $\quad 35$

Demographics $\quad 35$

Background Characteristics $\quad 35$

Educational Background $\quad 36$

$\begin{array}{ll}\text { Subjects Schooled Outside of the U.S. } & 37\end{array}$

$\begin{array}{ll}\text { Persistence in Pre-GED Studies } & 37\end{array}$

Persistence Rates Among Particular Groups $\quad 37$

Demographic Groups $\quad 38$

Parenting and Employment Status Factors $\quad 39$

$\begin{array}{lr}\text { School Experience and Persistence } & 40\end{array}$

Non-U.S.-Schooled Subjects 43

Other Adults in the Lives of Study Subjects 46

Current and Prior Adult Learning Experiences $\quad 51$

Supports and Obstacles $\quad 56$

Discussion of the Findings $\quad 58$

Lessons from Program Practice $\quad 63$

$\begin{array}{ll}\text { Intake } & 63\end{array}$

$\begin{array}{ll}\text { Orientation } & 64\end{array}$

$\begin{array}{ll}\text { Instruction } & 65\end{array}$

Program Activities $\quad 66$

$\begin{array}{lc}\text { Conclusions } & \mathbf{6 6}\end{array}$

$\begin{array}{ll}\text { Next Steps } & 71\end{array}$

$\begin{array}{ll}\text { References } & \mathbf{7 3}\end{array}$

Appendix A: Learner Motivation Study Information Sheet 79

Appendix B: Orientation Activity with Potential Interview

$\begin{array}{ll}\text { Participants } & 82\end{array}$

Appendix C: Orientation Acitivity with Potential Interview

Participants (One on One) 


\section{Appendix D: Program Participant Interview Guide 87}

Appendix E: Permission Form $\quad 98$

\section{ACKNOWLEDGMENTS}

Many people helped in the course of this research. Chief among them were the 150 adult students who participated in the study and the teachers and administrators in their programs who helped arrange interviews. Chaunda Scott was one of the data collectors and Lee Holcombe helped with the statistics.

Hal Beder, Allan Quigley, Steve Reder, and Fran Tracy-Mumford read an early draft and provided advice that has been incorporated into this draft.

In addition, numerous practitioners from around the country provided advice and direction to both the research design and the final report of this study. 


\section{EXECUTIVE SUMMARY}

A key difference between adult and child learners is that adults choose to participate in educational programs while children participate because of legal mandates and strong social and cultural forces that identify schooling as the proper "work" of childhood. In fact, most school-age students probably never seriously consider dropping out. Adults, on the other hand, must make an active decision to participate in each class session and often must overcome significant barriers in order to attend classes. Although some adults may come to an adult basic education (ABE), English for speakers of other languages (ESOL), or adult secondary education (ASE) program with very limited goals, most come with goals that require hundreds if not thousands of hours of learning activities to achieve. When possible, every adult education program should help adult students persist in their learning until they reach their educational goals.

The first phase of NCSALL's Persistence Study is using research as a tool to develop advice for practitioners on how to help adults persist in their studies. In addition, the study is developing advice for policy makers on how to structure funding and accountability systems in ways that will support persistence. The next phase of this study will test out this advice in real programs to see if it is effective and refine it based on this experience. In the first phase of this research, the study team read previous studies and related literature, talked with practitioners about how they have tried to help adult students persist longer in their studies, and interviewed 150 pre-GED students in New England to gain their insights into the supports and barriers to persistence. Most of the students were native speakers of English, but a few were immigrants whose English was sufficient to be in a pre-GED class.

The staff of the Persistence Study spent a lot of time working on their definition of persistence so that they could be clear about what they were trying to measure. They found persistence to be a complicated concept. Most of the literature on adult education defines persistence as the length of time adults attend a class or tutoring sessions, but learning may extend beyond attendance in a specific program. The definition of persistence used in this study is:

adults staying in programs for as long as they can, engaging in self-directed study when they must drop out of their programs, and returning to programs as soon as the demands of their lives allow. 
The study team interviewed learners near the beginning of their participation in a program and again four months later. A persistent learner was one who, at the second interview, was still in class, was no longer in class but was involved in organized selfstudy, or had transferred to another class.

From the point of view of an accountability system, student persistence ends when an adult drops out of a program. When an adult returns to a program after a lapse in attendance, the program may view that student as a dropout who has returned. The adult may view him- or herself as a persistent learner who couldn't attend for a while. From the point of view of the student, persistence may continue after dropout through self-study or distance learning. Using only attendance in class or in tutoring sessions as a measure of persistence undervalues effective learning activities that should be encouraged. A wider definition of persistence would allow practitioners to focus on helping adults become persistent learners who use episodes of program participation as critical parts of a comprehensive learning strategy that employs other forms of learning.

The definition developed by the study team in the Persistence Study values both self-study and transfer or reentry into a program as part of a pattern of persistence. For this expanded definition of persistence to become part of an accountability system, it must be measurable. This would require procedures for collecting evidence of "timeon-task" that could be credited to a program. Some of this "time-on-task" might be spent in classes, some in tutoring sessions, and some in self-study through technology, media, or instructional materials. Other "time-on-task" measures might include increased time reading or reading of new, more challenging materials and engagement in community improvement efforts that require the use of English, literacy, and math skills. Ways to measure and validate these efforts and link them to a plan of learning developed within a program context would transform some dropouts into persistent learners who are not presently attending formal classes or tutoring sessions.

This expanded definition would require programs to think of the relationship to their students differently. Programs would need added resources to stay connected and serve adults when they are not attending formal classes or tutoring sessions. With these added resources, programs could treat their students as long-term clients who use a range of services, some provided by the program and some by other agencies, to achieve significant improvement in their skills. Since a single adult student might participate in the services of several different programs, a way to document progress would have to be shared among them. 
This study found that the many ways in which we can classify adult students (by gender, ethnicity, age, employment status, number and age of children, previous school experience, and educational background of other adults in their lives) do not tell us much about how to help them persist in their education. The only significant findings were that immigrants, those over the age of 30 , and parents of teenage or grown children were more likely to persist than others in the study. The greater likelihood of persistence by immigrant students in ESOL classes is well documented, and the findings of this study suggest that this effect continues as immigrants learn English and move on to ABE and GED programs. Grown children might encourage their parents to join and persist in a program. On the other hand, adults who are over 30 are more likely to have teenage or grown children than those under 30 . These findings might point to older students persisting longer because they benefit from the maturity that comes with age and they no longer have the responsibilities of caring for small children.

Two aspects of educational experience were also associated with persistence. Adults who had been involved in previous efforts at basic skills education, self-study, or vocational skill training were more likely to persist than those who had not. The strongest relationship was with those who had undertaken self-study. Adults who, when asked why they had entered a program, mentioned a specific goal (such as help my children or get a better job) were more likely to persist than those who either mentioned no goal or said they were doing it for themselves. These findings suggest that experience with education may increase an adult's self-confidence about learning. These relationships also suggest that motivation, especially as demonstrated by undertaking self-study or by being clear about the goal for attendance, is a support to persistence.

The pre-GED students identified a wide range of supports and barriers to their persistence, but clear trends were evident when their responses were analyzed. The study team recorded these trends and then looked back at the literature it had reviewed and the experience of practitioners who had been interviewed and developed the following advice, which describes four supports to persistence.

The first support is management of the positive and negative forces that help and hinder persistence. In searching for a framework for analyzing data, the study team sought a theoretical model that would both place the adult learner in a central position and be useful to program managers who are seeking practical advice on how to increase persistence. The study team chose to employ a force-field analysis as developed by the sociologist Kurt Lewin. Lewin's theory places an individual in a field 
of forces that are supporting or inhibiting action along a particular path (Lewin, 1999; Gilbert, Fisk, \& Lindzey, 1998). Understanding the forces, identifying which are strongest, and deciding which are most amenable to manipulation provides an indication of how to help someone move in a desired direction, in this case reaching an educational goal.

In the case of adult students, there are positive forces (desire for a higher income, for example) that are helping support persistence in an adult education program. These forces help adults to continue their participation. On the other hand, negative forces (lack of free time to study, for example) are pushing adults to drop out. From the time adults enter programs to the time when they either achieve their goals or drop out, both positive and negative forces are acting upon them. Any intervention meant to increase persistence must help adults strengthen the positive forces and lessen the negative forces. The first step is to identify all the forces that are acting upon an individual. The next step is to identify which forces can have a significant effect on an individual's path. Of these strong forces, a determination must be made as to which ones can actually be managed or, rather, which positive forces can be made stronger and which negative forces can be made weaker.

The force-field analysis looks at these barriers and supports as existing at many levels of importance, from those that have no real effect on persistence to those that have a very strong influence on persistence. The force-field analysis also suggests that improvement in one force that can be influenced might offset the effects of another force that cannot be influenced. Thus, an adult with a very strong need for education to gain better employment might put aside his or her embarrassment, while very strong embarrassment might keep a less strongly motivated student from coming to class.

Programs must help students develop an understanding of the negative and positive forces that affect their persistence. Building on that understanding, each student must make plans to manage these forces so that persistence is more likely. The plans that come out of such an exercise should include strategies for persistence when the forces that affect a person's life cause that person to drop out, and these plans must be revised as adults persist in their studies and these forces change.

Adult students in this study emphasized positive forces. The strongest positive force mentioned by adult students was the support of people, particularly their families, friends, teacher, and fellow students, followed by self-efficacy and personal goals. Most learners mentioned at least three positive forces, while some mentioned many 
more. On the other hand, many learners mentioned no negative forces or just one. No single negative force was common.

The force-field theory itself offers a tool for understanding and planning to manage these forces. Students can be encouraged to discuss their persistence in terms of the force-field and to build their plan from that discussion. A classroom force-field activity can begin with students identifying all of the supports and barriers to their persistence. They can then categorize them into those that are most likely to help or hinder their persistence. Once the crucial forces are identified, students can plan to build their supports and lessen their barriers. As happens in some programs, staff must be open to having the outcome of this activity be early dropout for students who, for any reason, are not ready to persist in their studies. If this is the outcome, adults should be helped to make a plan to prepare to return and be successful later, if at all possible. The management of these forces may be an individual responsibility or it may be one that a group of students take on together or one that engages a whole community. For example, most students in a class might have transportation needs. A group activity might lead to ride sharing or a request to a public agency for transportation support.

The second support is self-efficacy. The educational program must help adult students build self-efficacy about reaching their goals. The term self-confidence is used more often in adult education literature, but self-efficacy is a more useful term to describe this support. Self-confidence is a global feeling of being able to accomplish most tasks. Self-efficacy is focused on a specific task and represents the feeling of being able to accomplish that task, which here is successful learning in ABE, ESOL, or ASE programs. The study drew from the theory of a social scientist, Albert Bandura, for advice on building self-efficacy (Bandura, 1986). Adult education programs should provide the following experiences to their participants as a means toward building selfefficacy:

- Mastery experiences are those that allow an adult to be successful in learning and to have authentic evidence of that success. This does not mean that instruction should be designed to produce only easy and constant success. Adults must also experience overcoming failure and eventually achieving success through a sustained effort, and instruction should help them develop this insight. Some programs take care to provide regular recognition of progress and celebrations of achievement. Others make sure that instruction provides opportunities for success early in program participation. These efforts provide learners with opportunities to experience success. 
- Vicarious experiences are those that are provided by social models. Adult learners should come in contact with adults who are just like them and have succeeded in an ABE, ESOL, or GED class. These role models, both through the knowledge they share directly and the indirect teaching of their behavior, help adult students acquire the skills to manage the many demands of the learning task. Some programs employ successful present or past students as speakers during intake and orientation activities, while others recruit past learners to be counselors, teachers, and directors. These past students provide models of success.

- Social persuasion is support from teachers, staff, counselors, fellow students, family, and friends that reinforces self-efficacy. These verbal assurances are needed, in part, to overcome the negative self-efficacy about learning built during schooling. Most practitioners provide verbal assurances, but some programs encourage family members to provide this positive reinforcement as well. Some teachers take great care to develop a culture of support among students in their classes. These efforts ensure positive support for students.

- Addressing physiological and emotional states helps students to deal with the tension, stress, and other negative emotional states that can result from poor selfefficacy and can also lead to low self-efficacy. Adult learners must be helped to perceive and interpret these feelings so that they do not affect their self-efficacy. Some practitioners feel uncomfortable with addressing the personal problems of their students, and all practitioners must acknowledge that they are not trained mental health professionals. Even so, many teachers use life histories and dialogue journals to help students identify the physical and mental health problems that can effect their learning. For example, adults with limited English proficiency are usually anxious about speaking in front of a class. A teacher can encourage the class to write about these feelings of anxiety and discuss ways to overcome them. The teacher can then help her students practice speaking even though they do have feelings of anxiety. Just the acknowledgment that life experiences affect learning can help diminish their negative effect.

Many of the orientation and instructional activities identified by practitioners in this study provide the experiences that Bandura has outlined. Bandura's theory of self-efficacy can act as a powerful framework within which programs can improve on the activities they have already undertaken. 
The third support to persistence is the establishment of a goal by the student. This process begins before an adult enters a program. An adult who could be classified as a potential ABE, ESOL, or ASE student experiences an event in his or her life that causes him or her to enter an educational program. That event might be something dramatic; for example, a well-paid worker might lose his or her job and find that he or she does not have the basic skills needed to qualify for a new job at a similar pay scale. That event might be less dramatic; for example, a parent may decide he or she needs more education when a first child begins school. That event might be subtle; for example, a school dropout might have always felt the desire to study for the GED but when his or her children are older and need less attention, there is finally some free time available for education. This event provides potential adult students with goals they hope to accomplish by entering an ABE, ESOL, or ASE program. The staff of the educational program must help the potential adult student define his or her goal and understand the many instructional objectives that must be accomplished on the road to meeting that goal. Teachers must then use those student goals as the context for instruction and revisit goal setting since they may change.

The Equipped for the Future initiative offers an approach to understanding and defining the educational objectives needed to reach the most common goals expressed by adults in this study. Other goal setting approaches might work as well, but one powerful factor in favor of EFF is that it focuses on the broader purposes of education, which include the adult roles of worker, family member, and citizen. Goals related to both work and family are certainly the most common in this study, but other goals such as EFF's category of citizenship are especially important to some learners. In the portion of the study that asked specifically about why each adult entered a program, a chronological string of goals was common. That full string of goals included "get a GED, go to college, get a better job, and help my children." Some people mentioned all of these, and some just mentioned a few. Those who only said "get a GED" might have added some of these other goals had they been prompted by a simple "Why?" Teachers should enter a continuous dialogue with each student that leads to a better understanding of goals by both of them.

The fourth support is progress toward reaching a goal. Since their goal is an important support to persistence, adult students must make progress toward reaching that goal, and they must be able to measure that progress. Programs must provide services of sufficient quality that students make progress, and programs must have assessment procedures that allow students to measure their own progress. Much of the recent interest in measuring progress has come from the need to build systems of 
program accountability. Helping students measure their own progress may need tools and methods that are not appropriate for accountability purposes. Accountability systems need measures that are easy to collect and quantify, and these may not be useful to students and difficult to integrate into instruction. Portfolio and authentic assessment approaches may have weaknesses in an accountability system but might be very useful for adults who want to measure their own progress. These kinds of assessments can be an integral part of an instructional approach.

Further research into assessment might produce a hybrid system that serves both needs and could lead to certification of progress that occurs more frequently than it does at present in most programs. At this time, most adults who enter ABE, ESOL, or ASE programs will gain certification only if they pass the GED test or acquire an adult high school diploma. Program level certification may be helpful to student morale, but state-level or even national certification of achievement might make smaller increments of learner achievement more meaningful and provide a range on goal steps.

Policy Support to Persistence. Aspects of these four supports already exist in some programs, but a combination of the four may provide a more supportive environment to persistence. These supports are more likely to be built if the policy makers who provide funding value them. This means that persistence must become a more important measure in program accountability, and funding agencies must provide the technical assistance and training needed for programs to put these supports in place. Policy makers could then hold programs accountable for the quality of their intake, orientation, instruction, and program approaches that support persistence. Using the expanded definition presented here, persistence itself should be an outcome that is measured as part of an accountability system 


\section{PERSISTENCE AMONG ADULT BASIC EDUCATION STUDENTS IN PRE-GED CLASSES}

\section{INTRODUCTION}

In 1992, the National Adult Literacy Survey (NALS) divided the U.S. population into five levels of competency in relation to a test of reading and math skills. According to the NALS, 21 to 23 percent (approximately 40 million people in 1992) of the U.S. adult population would score in the lowest level on its test, and an additional 25 to 28 percent (approximately 50 million people) of the adult population would score in the second lowest level (Kirsch, Jungeblut, Jenkins, \& Kolstad, 1993). In Teaching The New Basic Skills, Murnane and Levy (1996) identified 9th grade reading, writing, and math skills (along with communications, problem solving, and computer skills) as essential for economic success in today's workplace. Most of the 50 million adults who fall into the second of the two lowest NALS levels do not meet these criteria, and the 40 million who fall into the lowest level are extremely disadvantaged in relation to this benchmark.

A literacy score in NALS levels 1 or 2 is not the only indication that someone is educationally disadvantaged. Approximately 40 million adults lack a high school credential (NCES, 1997), and 6 million adults, many of whom are literate in their own language, lack English language literacy (NCES, 1997). The potential adult population that might benefit from programs that would help them improve their basic skills, learn English, and acquire a high school diploma, therefore, may be greater than 90 million. Even if half of this population would never choose to participate in an adult education program, the pool of potential participants would be approximately 50 million, which is equivalent to all the students presently in the K-12 system (NCES, 1997).

In 1997, approximately 4 million adults sought to improve their literacy skills, increase their English language fluency, or acquire high school credentials in adult education programs that have some federal funding. (Elliott, 1998). These programs are usually identified by the terms Adult Basic Education (ABE) for those seeking to improve literacy and math skills, English for Speakers of Other Languages (ESOL) for those seeking to improve English skills, and Adult Secondary Education (ASE) for those seeking a high school credential. ASE programs include those that provide an adult diploma through a school system and those that help adults to study for the General Education Development (GED) test, which is equivalent to a high school 
diploma.

According to the National Evaluation of Adult Education Programs (NEAEP), ${ }^{1}$ 50 percent of the adults who enroll in ABE classes (and attend for at least one hour) drop out before completing 35 hours (10 weeks) of instruction (Young, Fleischman, Fitzgerald, \& Morgan, 1994a). The median hours of instruction for ESOL students is higher at 113 (16 weeks) and lower for ASE students at 28 ( 8 weeks) (Young et al., 1994a). Only about 11 percent of ABE and 9 percent of ASE students attend classes continuously for a year, while approximately 25 percent of ESOL students attend for the same time period (Young et al., 1994a). The low persistence rate among ABE, ESOL, and ASE students places a severe limitation on how much progress they can make.

This paper is part of an effort to understand better how to increase persistence in ABE, ESOL, and ASE programs. The paper presents a summary of previous research, presents findings from new research that explores the forces that support and inhibit persistence of adult students, describes and analyzes programmatic and instructional attempts to address these forces, and draws conclusions for policy, practice, and further research.

In Rethinking Literacy Education, Quigley (1997) suggests that the answer to the question of how to improve persistence will come from asking adult learners. The new research reported here took that advice and interviewed 150 adults who were in adult education programs in five New England states. In choosing the study population, the research team struggled with where to begin. The population in adult education programs is diverse, and a study sample that includes enough people from each group (several levels of ESOL and ABE along with ASE students) is impossible with the limited resources available to this study. The research team chose to limit the sample to adults in classes identified as "pre-GED."

People studying for the test in a GED class usually have a limited amount of time to prepare for it. Adults who are below the pre-GED level usually have very low reading skills and may have a high incidence of learning disabilities (Reder, 1995). This group usually needs years of study to reach a significant goal such as passing the GED test. People in pre-GED classes are in the middle of these two extremes and offer a

\footnotetext{
${ }^{1}$ Although the NEAEP study has been criticized on methodological grounds (Beder, 1999), it offers the only national statistics available at this time.
} 
good group with which to begin research into persistence. Pre-GED students need a significant amount of study time to achieve a goal such as passing the GED test, but they are less likely to have severe learning disabilities. Some people in pre-GED classes are non-native speakers of English, but since they have sufficient English fluency, they are no longer eligible for ESOL classes, which mostly serve students who are just learning English. Further research will be needed to test the findings of this study to see if they are applicable to adult students who do not fall into the pre-GED category.

\section{PERSISTENCE}

A key difference between adult and child learners is that adults choose to participate in programs while children participate because of legal mandates and strong social and cultural forces that identify schooling as the proper "work" of childhood (Cross, 1981; Knowles, 1970). Most school-age students probably never seriously consider dropping out. Adults, on the other hand, must make an active decision to participate in each class session and often must overcome significant barriers in order to attend classes.

A goal of every adult education program should be to help students persist in their learning until they reach their educational goals, but persistence in learning may extend beyond attendance in a specific program. When students must drop out of a program, they may still persist in learning through self-study or distance learning. Persistence in learning may also include a return to a program after a lapse in attendance. The definition of persistence in this paper incorporates all of these possibilities. Persistence is defined here as:

Adults staying in programs for as long as they can, engaging in self-directed study when they must drop out of their programs, and returning to a program as soon as the demands of their lives allow.

Persistence is a continuous learning process that lasts until an adult student meets his or her educational goal.

For the purposes of adult education research, persistence is usually measured as participation in formal classes or one-on-one tutoring sessions. The more inclusive definition of persistence used here is more difficult to measure. Dropouts from adult literacy classes are often difficult or impossible to contact, and this makes the 
measurement of persistence after dropout imprecise. Since dropouts are difficult to contact, a persistence rate that is based on attendance records will always be less than the persistence rate as defined in this paper. Although time in class or in tutoring may not be meaningful for an individual student, it is probably a good measure of persistence for comparison between populations of adult students, which makes it useful for research into factors that support or inhibit persistence. Research into persistence must depend on measures that can be collected, and time in class or in tutoring is the only effective measure available at this time.

The NEAEP study (Young, Fleischman, Fitzgerald, \& Morgan, 1994b) interviewed 3,403 adults who had left ABE, ESOL, and ASE programs. Of the total, 41 percent reported that they left satisfied and 45 percent left because of noninstructional factors such as a lack of transportation, a loss of child care, or a change in job schedule. Only 7 percent reported leaving because of instructional factors, while 7 percent left for a combination of reasons or gave no reason. NEAEP found that most dropouts left their programs within the first 12 weeks of instruction. However, participants who stayed more than one month were likely to persist for 45 percent longer than those who did not complete one month, and this differential in persistence increased as more months of participation passed. Those who stayed past the first month were likely to stay for eight months. Since many programs operate on an academic schedule, eight months may indicate completion of one full year of study by a committed participant who may return for a second year. These findings from NEAEP support Quigley's (1997) contention that the first three to six weeks of program participation are key to persistence.

NEAEP data were collected over a twelve-month period in 1991 and 1992 and represent a cross-section of participation in specific programs. These findings may not paint an accurate picture of each individual's pattern of participation. That is, some of the people identified as dropouts after a few weeks may have returned to that program or entered another program during that year. In addition, adults with shortterm participation one year might go on to participate again in that program or in another program the next year. A study of ESOL students in California, for example, suggests that 25 percent of those identified as dropouts may actually have transferred to other classes (Sticht, McDonald, \& Erickson, 1998).

During approximately the same time period (1991-1992) as the NEAEP study, the Basic Skills Unit in Great Britain studied 176 students and 64 teachers. The next year they studied another 1218 students and 59 teachers. This study found that 
approximately 50 percent of the students dropped out in the first six weeks, with 30 percent dropping out in the first 3 weeks. The data collection procedures and methods of analysis used in this study and the NEAEP are quite different, but the comparison does indicate that high dropout rates are not a phenomenon unique to the U.S. (Kambouri \& Francis, 1994).

The low persistence rate reported in NEAEP places a significant limitation on the benefits of classroom instruction. Several studies have determined that approximately 100 hours of instruction are needed for an increase of one grade level equivalent on a standardized test (Darkenwald, 1986; Sticht, 1982), but most adult participants are not in class for 100 hours. Although some adults who enter ABE, ESOL, and ASE programs may have specific goals that require only a few hours of instruction, most would benefit from a sustained, long-term effort.

The NEAEP study found that 44 percent of ABE, ESOL, and ASE participants left their programs satisfied, but only 5 percent left having achieved their goal. Since adults are leaving programs before completing the 100 hours needed to make measurable progress and are reporting that their goals have not been achieved, improving persistence rates is critical for any effort to increase program impact. ASE students had the highest percentage of satisfied students at 54 percent, ABE was next at 41 percent, and ESOL was least at 29 percent. These findings are interesting in that satisfaction appears to be inversely related to hours or weeks of instruction.

Common sense argues that there must be a relationship between length of time in class and achievement, but NEAEP (Young et al., 1994b) found no direct relationship between persistence and improvement in scores on the Test of Adult Basic Education (TABE) for ABE and ASE participants. Since ASE students had already scored high on the TABE, an increase in score was probably unlikely. NEAEP did find a relationship for ESOL participants on the California Adult Student Assessment System (CASAS) reading test. In another study, Perin and Greenberg (1993) found a relationship between weeks of instruction and scores on writing and math tests, but not on tests of reading. Their population, however, was comprised of adults who had either a high school degree or a GED certificate and were preparing for college-level course work. These participants may have had reading levels that were too high to show any benefit within a limited time of instruction. Comings (1995) found a relationship between duration of study and achievement and skill retention in literacy programs in Third World settings, but these findings may not be applicable to the U.S. population. 
The difficulty of measuring learning gains in this population complicates the discussion of the relationship between persistence and achievement. Non-ESOL adults with low literacy skills may have learning disabilities that interfere with assessment of achievement. ESOL adults who are not literate in their own language may have trouble learning to read in a language they do not fully understand. If achievement comes slowly, existing tests may not provide the sensitivity needed to measure learning gains, particularly since many of the teachers who administer the tests have little or no training in test administration (Beder, 1999; Condelli \& Kutner, 1997; Young, et al., 1994b). Even the finding that 100 hours of instruction leads to an increase of one grade level equivalent on a standardized test is suspect. There are many factors other than achievement that might result in a one grade level increase, and there are no reports that continued hours of instruction result in similar gains. The one grade level increase after 100 hours may be influenced by familiarity with the test that developed after the first measurement or may be the result of adults feeling more relaxed for the second test.

Given the many unanswered questions about achievement in ABE, ESOL, and ASE classes, common sense may be the only way to approach this issue. More time on task should produce more positive benefit. Adults who would score in the bottom two of the five NALS levels probably need hundreds, if not thousands, of hours of study and practice to raise their skills to a level that would make dramatic changes in their ability to perform the adult roles of worker, parent, and citizen. Understanding how to help adults persist in their studies, therefore, is key to increasing the impact of adult education programs. In addition, three different research agenda setting exercises (Bickerton, Comings, Shields, \& Waldron, 1995; CAL, 1998; NIFL, 2000) identified learner motivation to persist as one of the most important research questions that need to be addressed to improve ABE, ESOL, and ASE programs. In these three agenda setting exercises, adult students, teachers, administrators, and policy makers all emphasized the importance of this issue.

Since ABE, ESOL, and ASE programs in the United States do not have sufficient resources to serve either the potential or the actual demand (Venezky \& Wagner, 1994), encouraging more people to join these programs is not a pressing issue. Rather, understanding how to ensure that those who enter can persist and succeed is more important at this time. Boshier (1973) suggests that non-participation and dropout are similar phenomena, while Quigley (1997) sees participants and non-participants as two distinct populations. Even though persistence might be the more important issue, a complete understanding of this phenomenon may require an understanding of the decision either to enter a program or to remain a non-participant. Although this paper 
draws from the literature on the decision to participate, the new research presented here focuses on adults who have already begun participation. 


\section{LITERATURE REVIEW}

New research on persistence is hampered by the lack of previous research in adult education. Much of the adult education literature on persistence or related topics draws on research with adults who have sufficient literacy skills, speak English, and have high school degrees. Although this research is informative, it may not be directly applicable to ABE, ESOL, and ASE students. In addition, most of this research is on people who are in short-term courses with defined, limited goals. Most ABE, ESOL, and ASE students are facing a long-term commitment that may involve many different goals. These studies, too, are informative but do not necessarily provide insights into how to help adults persist in their studies for as long as it may take to make real progress.

Several scholars have published excellent reviews of the literature on motivation, retention, persistence, dropout, and participation in adult education programs (Beder, 1991; Wikelund, Reder, \& Hart-Landsberg, 1992; Tracy-Mumford, 1994; Quigley, 1997). This study draws on these four reviews. For those interested in an exhaustive review of the literature related to persistence, a reading of these four sources provides that opportunity. This paper summarizes these four reviews to provide a foundation for understanding the student interview data that follows.

Beder (1991) provides a comprehensive and thorough review of all sources that examine an adult's decision to participate in adult education. The review first explores motivation as the force that helps adults overcome the many barriers to participation that their lives impose upon them and then explores the deterrents or barriers to participation. Beder suggests that adult education programs must change their recruitment and instruction practices to be congruent with the motivations and life contexts of adult learners. If they do, more adults will enter programs, and they will persist longer. Beder describes seven models of motivation and then draws conclusions for adult education from each. These models are summarized below.

In the first model, Miller (1967) uses Lewin's (1999) force field analysis to identify positive and negative forces acting on motivation. Miller suggests that membership in a low socioeconomic class limits the motivation of adults who need training in basic skills. Although Beder criticizes this position, he does acknowledge that adult education programs that attempt to help poor people achieve success may be limited by the social class structure that contributes to the under-education of many adults. 
In the second, Boshier $(1973,1977)$ sets forth a congruence model in which there are two groups of adult learners based on the strength of their motivation to participate in education. The first group is made up of growth-oriented adults who are motivated by internal forces and whose view of themselves is congruent with their view of an ideal self and how others see them. Growth-oriented adults are open to new experiences and enjoy participation in education. Deficiency-oriented adults are motivated by external factors and have a view of themselves that is incongruent with their view of an ideal self and how others see them. Anxiety engendered by this incongruence leads deficiency-oriented adults to avoid participation in education.

In the third, Rubenson (1977) sets forth an expectancy-valence model to explain motivation to participate. Expectancy is an adult's perception that participation will be successful and beneficial. Valence is a measure of the costs of participation. In this theory, adults are weighing these two sides of an equation in making a decision to participate.

In the fourth, Cross (1981) sets forth a chain of response model to explain motivation to participate. This theory assumes that participation is the result of a series of steps. First, adults make a self-evaluation related to their confidence in undertaking this new activity. In the second step, the adult learner runs up against his or her attitudes toward education, which might be positive or negative. In the third step adults come to understand two aspects of their goal for participation. The first is the importance of the goal to the individual and the second is his or her belief as to whether or not the goal will lead to a reward.

In the fifth, Mortimer and Simmons (1978) set forth a socialization model that suggests that the problems caused by adult socialization create the motivation to participate. In adulthood, socialization takes place within roles such as worker, parent, and citizen. Motivation to participate in adult education, therefore, would come from real and immediate needs to fulfill an adult role. These needs may be the result of changes in the context of the adult or of changes in the society in which the adult lives.

In the sixth, Beder draws from Kotler (1975) and Beder (1980, 1986, 1990) to set forth a demand model that suggests that adults participate when the value they will gain is greater than the resources they must put into their studies. To support persistence, programs need to lower the "cost" (in terms of time and effort) by making adult learning easier and more convenient while increasing its value by, for example, 
making it more likely to lead to higher wages or recognized certification.

In the seventh, Freire (1970) sets forth a critical pedagogy model that does not focus specifically on motivation, but does critique the ways in which motivation is understood. In critical pedagogy, motivation is socially constructed. That is, the psychological state of motivation is a product of the social context of the adult. If a disenfranchised group has low motivation, it is not the result of personal deficiencies but, rather, the outcome of oppression within an unequal society. The group of disenfranchised must come together to socially construct a context in which their motivation can flourish.

Beder also reviews descriptive research that explores the motivations of adult learners and potential adult learners. He points out that this body of research (Boshier, 1971; Boshier, 1977; Hill, 1987; Houle, 1961; Johnstone \& Rivera, 1965) draws data from adults whose educational level is higher than that of most potential ABE, ESOL, and GED students. The adults in these studies report motivations to attend educational programs that are short-term and have limited objectives. Even if some of the subjects of this research do fit into the ABE, ESOL, and GED population, the studies cannot make that differentiation.

To make up for this deficiency, Beder reports descriptive data on the $\mathrm{ABE}$ population in Iowa (Beder \& Valentine, 1987) that found their motivations to be about the same as those reported by studies of the general population. Since the adults who were sampled in the Iowa study had joined an ABE program, they could be different from those who have low basic skills but had not yet joined a program. Even if this is so, similarities between ABE participants and better educated adults are important since they suggest that a theory of persistence could draw from research on the general population. Beder also reports on other studies of ABE and ESOL students (Bova, 1985; Fingeret, 1985; Mezirow, Darkenwald, \& Knox, 1975). From these studies, he develops ten motivations: self-improvement, family responsibilities, diversion from everyday life, literacy development, community/church involvement, job advancement, launching into full adulthood, economic need, educational advancement, and response to the urging of others.

In discussing deterrents to participation, Beder first looks at efforts to categorize and describe them. He begins with Johnstone and Rivera (1965) who suggest two categories. Dispositional barriers are those related to personal attitudes about participation such as negative attitudes about education. Situational barriers are outside 
the individual and include such things as availability of classes and knowledge of that availability. Darkenwald and Merriam (1982) break dispositional barriers into two components, informational and psychosocial. Informational barriers result from a lack of information about availability of education. Psychosocial barriers result from attitudes and values.

Beder then looks at deterrents research that attempts to identify barriers (Blais, Duquette, \& Painchaud, 1989; Darkenwald \& Valentine, 1985; Martindale \& Drake, 1989; Scanlan \& Darkenwald, 1984). These studies produce similar lists that include financial cost, lack of confidence, time constraints, lack of interest, and lack of course relevance. Beder concludes that these different barriers are influenced by characteristics of the individual adults. As with other studies in this area, this research was not focused directly on the ABE, ESOL, and ASE population, and the characteristics of this less-educated group might lead to a different list of barriers.

In a creative application of marketing theory, Beder returns to the concept of "demand" and lists five factors that might constrain demand: competition, product, price, promotion, and location. He suggests that demand can even be negative. Competition can take the form of other activities, such as work, that are competing for the time needed to study in a program, but competition can also take the form of alternative ways of overcoming a skill barrier. Beder refers to Fingeret (1983) who notes that some low literate adults use the literacy skills of their family members and, therefore, do not need to acquire the skills themselves. The product, for the most part, resembles school and Beder points out that many adult learners harbor negative feelings about school. The product can also be defined by its benefits and some of the benefits, such as increased income, might more easily come from other sources. Promotion is defined as the activities done to make adults aware of and interested in services. Given the chronic underfunding of this field, Beder suggests that promotion is not usually done well, if it is done at all. Barriers of location include inconvenience, but Beder points out that even when it is convenient, a school venue can be a deterrent if adults have negative feelings about school or feel childish studying in a school building. Beder suggests that a framework that mixes positive approaches to all of these factors might produce higher participation.

Beder suggests that even when the mix of marketing factors is positive, some adults may still resist participation. He refers to research by Quigley (1990) that is based on interviews with a small sample of adult learners and representations of school resisters in fiction, as well as a study by Willis (1978) of English school resisters. These sources suggest that negative school experience or membership in a subculture of school 
resistance can act as a barrier, even to well designed and implemented programs. Resistance can even be part of a larger economic culture that must consign some people to low wage jobs.

Beder finishes his review by building on two studies that looked at the barriers from the point of view of participants and potential participants. Hayes (1988) identified five factors: low self-confidence, social disapproval by friends and family, negative attitudes towards adult literacy, and low personal priority. Beder (1990) identified four factors: low perception of need, perceived effort, dislike for school, and situational barriers. Together, these studies point to perceptions by some adults that they may not benefit from participation, may not be able to learn, do not like participating in formal learning programs, and are unwilling to overcome the many barriers to participation. This describes a powerful set of negative forces that keep adults from entering or persisting in adult education programs.

Beder suggests that there may not be a lot that can be done about low perception of need. For many adults their perceptions may be correct. Perceived effort may be formed by low self-confidence in relation to the task, which is perceived as extremely difficult by some. Again, Beder suggests that this view is accurate for many adults. Improving reading, writing, math, and English skills to the point where an adult can be successful on the GED can be a very difficult task. In addition, finding the time and energy to take part in classes and individual study is difficult for people who also have the adult responsibilities of family, work, and community. These situational barriers to participation are real and can be daunting, and programs that look too much like school rekindle memories of the negative experience of school many adults carry with them.

Beder concludes by making suggestions about dealing with nonparticipation. He opens by acknowledging that the system, at this time, probably only has enough resources to serve those who are eager to enter classes. This position, he notes, does not pay attention to the social costs of an undereducated population and the socialization process that leads many of these adults to be uninterested in further education. Although education can never be easy, Beder suggests that the effort could be more manageable if programs had the resources to fit instruction to the needs and learning styles of adults. The same can be said for making adult programs less like school and more like an activity in which adults would want to participate.

Wikelund et al. (1992) draw from the same sources as Beder, but they 
critique the reductionist tendencies of research and suggest that a useful theory of participation would incorporate the complexity of this phenomenon. The paper calls for broadening the definition of participation to acknowledge that adults engage in education in many ways that are not limited to participation in formal classes. This review explores the ways in which existing research and theory fail to provide programs with useful models for defining participation.

On motivation research, Wikelund et al. point to Beder and Valentine (1990) who speculate that, beyond any specific goals uncovered by their Iowa study, participation in ABE, ESOL, and ASE classes may also be a symbolic activity needed to develop a sense of self-confidence. This self-confidence is low because of failure in school or a feeling of inadequacy from being unable to speak English. The motivations described in the Iowa study are real, but there may be hidden motivations, some of which may be more important in supporting persistence. Wikelund et al. present the theory, developed by Bandura (1986), that individuals form expectations about what situations may arise and what their outcomes may be and then make decisions to act or not based on those expectations. Bandura emphasizes self-direction and self-regulation, which are parts of a larger concept of self-efficacy, as key to motivation.

The discussion of motivation ends with a statement that none of the theories or descriptive studies integrate all of the complicated and interrelated forces that work on the decision to participate. But the attempts to include all of the possible forces and take into account the interaction among them have been unsuccessful, and that may suggest that no simple theory can explain this situation (Merriam \& Caffarella, 1991).

On deterrents research, Wikelund et al. caution that a well-defined list of deterrents will not explain why two adults, both of whom have the same deterrent in their lives, might have very different participation patterns. They also make note of Benseman (1989) and Fingeret (1983) who point out that deterrents research has taken the institutional view that barriers are always negative. Students may define some of these barriers as positive. The example given is the demands of family life, which from the institution's perspective is a negative barrier to participation but from the student's perspective is a positive support in their life.

Wikelund et al. criticize the concept of "non-participant" because it implies that every adult who has low literacy skills needs to enter a program, a situation that might not be true, but suggests that research on nonparticipants has some value for the field. After reviewing several of the studies that are quoted in Beder (1991), they end with a 
later Beder (1992) article that identified three categories of nonparticipants. The first is the "demand population," who are motivated to participate and who have no significant barriers to that participation. The second is "motivated but constrained" who are motivated but who have external barriers such as a lack of childcare keeping them from attendance. The third is "resisters" who are not motivated to attend.

Wikelund et al. (1992) complement Beder (1991) by coming to a similar conclusion from a different path. Still, the conclusions are based on the same foundation. The review ends with the conclusion that research and theory, as well as practice, should break out of the framework of schooling. A new definition of participation would acknowledge that learning, even improvements in literacy skill, takes place outside of formal programs. With this new definition, programs can increase persistence by continuing to support learning at times when students cannot attend classes. Classes can serve as part of an instructional process that involves other aspects of a student's life.

Tracy-Mumford (1994) focuses her review on retention and summarizes the findings of a large number of studies in order to offer advice on how to improve program quality. This review calls for programs to develop a commitment to and a plan for increasing retention. A program commitment to retention, Tracy-Mumford suggests, sends a strong message to students that the program is there to help them reach their goals. Since student goals can change, the program must be willing to make changes to accommodate new goals as they arise. For the commitment to be meaningful, the program should have a set of criteria for measuring persistence and defined strategies that reduce dropout, increase student hours of attendance, improve achievement, increase personal goal attainment, and improve completion rates.

Tracy-Mumford defines an effective retention plan as one that provides support to students and improves instruction. The review summarizes all of its findings with a list of elements of a student retention plan that weaves retention strategies into all aspects of the program structure. This advice is:

- Recruitment should provide enough information that potential students can make an informed decision about enrolling.

- Intake and orientation should help students understand the program, set realistic expectations, build a working relationship with program staff, and establish learning goals.

- Initial assessment should provide students and teachers with information on both 
cognitive and affective needs, should be integrated with instruction, and should form the foundation for measuring progress.

- Programs and teachers should recognize student achievement.

- Counseling should identify students at risk of dropping out early.

- Referral services should coordinate with other agencies to ensure that all students are connected to the support services they need.

- A system for student contact and follow up with dropouts should help students return to the program and provide information on ways to improve service.

- Non-instructional activities should help form a bond between the program and its students and their families.

- Program evaluation should involve students in assessing and offering advice on each aspect of the program.

- Child care and transportation assistance should be provided.

- Instruction and instructional staff should be of sufficient quality to support effective learning.

- Student retention teams should coordinate dropout prevention activities, collect data on student retention, and involve students and teachers.

Tracy-Mumford's list is comprehensive and is useful because it translates theory into practical advice. Most programs lack the level of funding that would allow them to follow all of this advice, but following some of the advice may contribute to increased persistence. Funding a demonstration program that incorporates all of these activities might prove that the added costs are, in fact, a reasonable investment.

Quigley (1997) views persistence as significantly affected by the negative schooling experiences adult learners had when they were younger and suggests the need to change programs to be very different from those schools. Quigley sees three major constellations of factors that contribute to dropout, which he refers to as situational (influences of the adult's circumstances), institutional (influences of systems), and dispositional (influences of experience). He suggests that the societal factors involved in situational influences are largely beyond the control of adult education programs, though they receive most of the attention in the literature on dropouts. Institutional influences, he says, are areas that practitioners need to work on continuously. However, the dispositional influences, he believes, provide a place from which program reform might begin to affect persistence.

Quigley focuses his attention on adults who drop out in the first few weeks of a program and to the dispositional influences that he believes cause that drop out. He 
believes that situational barriers have been overcome by adults before they arrive at a program, and though those arrangements may fall apart later, they have little effect in the first few weeks. Institutional barriers, too, have been overcome and, if they still exist, will have an effect later as they cause problems that build up over time.

The dispositional barriers, Quigley points out, were first thought to be deficiencies of the adult (Johnstone \& Rivera, 1965; Reissman, 1962). Later, cultural and value differences between well educated and less well educated adults were given as the explanation for these barriers (Fingeret, 1983, 1985; Quigley, 1990). The influence of prior schooling has since been identified as a major source of these barriers (Beder, 1991; Cervero \& Fitzpatrick, 1990).

Concluding that at least one third of incoming students are at risk of dropping out in the first three weeks of instruction, Quigley reports findings from two studies of incoming students he undertook. In these studies, Quigley tried three interventions: intensive support by a team of teachers and counselors, smaller classes, and one-onone tutoring. The small-group approach produced the highest persistence, followed by the team approach, and then one-on-one tutoring. All three had higher persistence than the comparison group, which attended the regular class program.

A possible explanation for the effect of the small group approach comes from the results of the administration of the Witkin Embedded Figures Test (Witkin, Oitman, Raskin, \& Karp, 1971) to the students before the experiment. Quigley explains that the Witkin provides an indication of whether or not a person is field dependent (a high need for acceptance, belonging, and harmony in the environment) or field independent (little need for such support). All the students had been rated independently by two counselors as "at-risk" of dropping out, and the group as a whole scored extremely high for field dependence on the Witkin. Similar results are reported by Donnaruma, Cox, and Beder (1980). The small group setting may provide the support, acceptance, and harmony these adults need for success in learning.

Quigley suggests that the intake and orientation processes of the first three weeks are critical to improving persistence. He suggests that intake begin with goal setting and planning for success. Students then need to be matched to classes and teachers that can meet their goals and learning needs. Since students are adults, they can take charge of this process, but they may need help in the form of careful questions and the provision of useful information for making these decisions. Quigley reiterates his belief that the prior history of negative experiences with school is an important factor 
that needs to be addressed during this critical first three weeks of instruction. He concludes his 1997 work by encouraging practitioners to study and then test his findings through practitioner research that employs methods such as action research and participatory research.

\section{THEORETICAL FRAMEWORK}

In searching for a framework for analyzing data, the study team sought a theoretical model that would both place the adult learner in a central position and be useful to program managers who are seeking practical advice on how to increase persistence. The study team chose to employ a force-field analysis as developed by the sociologist Kurt Lewin. Lewin's theory places an individual in a field of forces that are supporting or inhibiting action along a particular path (Lewin, 1999; Gilbert et al., 1998). Understanding the forces, identifying which are strongest, and deciding which are most amenable to manipulation provides an indication of how to help someone move in a desired direction, in this case reaching an educational goal.

In this case, the adult learner is the central character in the force field. If adult learners are passive, the forces will push them in one direction, which might be away from their goal. If adult learners are aware of the forces, they can take action to manage them so that these forces help to propel them toward their goal. Positive forces help adult learners persist and negative forces work against persistence. Positive and negative are not value judgements about the individual forces but indications of their direction. In this study, positive forces are those that are supportive of persistence, while negative forces are those pushing an adult toward dropping out. The individual forces may be viewed differently or even as benign outside of this context. For example, the demands of parenthood may be a negative force working against persistence in a literacy program, but parenthood and its demands are, for most people, very positive experiences.

One way to understand this framework is to think about children who are within the age of compulsory schooling (6 to 16 years in most U.S. states). These children have a very strong positive force supporting their persistence, the legal mandate that children must attend school until the age of 16. There may be other positive forces (a love of learning or helpful parents, for example) that are supporting their persistence, but this legal force is strong enough to support persistence even for those who have no 
other positive force supporting their participation. There may, in fact, be many negative forces acting on these students. Some of their teachers might be incompetent or even abusive, the school curriculum may be irrelevant to their everyday lives, and they may have to forgo opportunities to earn money, but they continue in school anyway.

After the age of 16, most students in the U.S. are supported in their persistence by social and cultural forces. These forces include the expectations of their peer group or family and their desire to spend time with their friends who are in school. There may be many negative forces working against continued participation, but only about 3.5 percent of high school students drop out each year (NCES, 1997). For most high school students who are over the age of compulsory attendance, the positive forces supporting persistence appear to be greater than the negative forces.

In the case of adult learners, positive forces (desire for a higher income, for example) help support persistence in an adult education program. These forces help adults to continue their participation. On the other hand, negative forces (lack of free time to study, for example) push adults to drop out. From the time adults enter programs to the time when they either achieve their goals or drop out, both positive and negative forces are acting upon them. Any intervention meant to increase persistence must help adults strengthen the positive forces and lessen the negative forces. The first step is to identify all the forces that are acting upon an individual. The next step is to identify which forces can have a significant effect on an individual's path. Of these strong forces, a determination must be made as to which ones can actually be managed or, rather, which positive forces can be made stronger and which negative forces can be made weaker.

Although Beder (1991) does discuss Miller's (1967) use of Lewin's force-field theory, none of the four major reviews employ a force-field analysis. The force-field identifies the same factors as noted in these four reviews, but presents them as continuous variables (ones that have many degrees of strength) rather than categorical variables (ones that either are or are not present). For example, Beder (1991) cites a study by Van Tilberg and Dubois (1989) that solicited supports and barriers to participation among $29 \mathrm{ABE} / \mathrm{GED}$ students in the U.S. and 29 students in programs that lead to certification exams in the U.K. In the report of this study, the barriers are listed as embarrassment, low anticipation of success, and previous negative educational experiences. Supports to participation were listed as needing an education for a job, desiring self-improvement, feeling concern for children, and avoiding current conditions. The force-field analysis looks at these barriers and supports as existing at many levels of 
importance, from those that have no real effect on persistence to those that have a very strong influence on persistence. The force-field analysis also suggests that improvement in one force that can be influenced might offset the effects of another force that cannot be influenced. Thus, an adult with a very strong need for education for a job might put aside his or her embarrassment, while very strong embarrassment might keep a less strongly motivated student from coming to class.

All four reviews suggest Cross' (1981) framework, which categorizes barriers as either situational (having to do with the life of the adult), institutional (having to do with the program), or dispositional (having to do with the attitudes of the learner). This study builds on this framework to develop a common way of categorizing both positive and negative forces and changes the categories in a way that might be more helpful to program managers who are trying to address this issue.

The four categories created for this study are personal, life-context, instructional, and program. Personal forces are those that adults bring with them to class in the form of attitudes, motivations, likes, and dislikes. These are the forces that Quigley (1997) encourages the field to focus on. Life-context forces are those that are in the everyday life of adult learners and include such things as transportation, day care, support of family and friends, and health. These are the forces identified in most studies as important. Instructional forces are those that take place within the class or tutoring arrangement and include such things as the teacher, support of other students, the curriculum and materials, and positive and negative feedback. Program forces are those that are outside the classroom but part of the educational program such as counseling, scheduling, location, program culture, and physical setting. These last two, instructional and program, expand the institutional barriers of earlier studies in a way that the authors felt would be helpful to program improvement. 


\section{METHODOLOGY}

Although all the negative and positive forces uncovered in the review of previous research could be important to persistence, some are probably more critical than others. To explore this question, the research team interviewed 150 adult learners in 19 pre-GED classes in 15 Adult Basic Education programs in five New England states. To identify program sites, the research team limited its search to an area that was within a two-hour drive of Boston. Several exceptions were made to the two-hour rule in order to assure that the sample included students living in both urban and rural areas. Since participation required cooperation and time of one or more staff members from each program, the research team sought programs that had staff willing to participate. The states of Massachusetts, Rhode Island, Vermont, New Hampshire, and Maine are within a two-hour drive from Boston, and so the research team contacted the ABE Directors from these five states. The Directors suggested advertising in state ABE newsletters and provided contact lists for their states' programs. These sources produced contacts with 17 programs that agreed to participate in the study.

The research team planned to interview 220 students who would provide a balance of white, African American, Hispanic, urban, and rural adults. The actual number interviewed was only 150 because two programs that agreed to participate canceled at the last minute. In one case the cancellation was caused by illness and in the other by time constraints. Because these programs canceled in the first data collection phase, there was insufficient time to reschedule. The cancellation of these two programs accounts for the low number of African-American and Hispanic subjects, since many of the students in these programs were from these two ethnic groups.

Potential study participants were identified through a teacher or program coordinator. Each study participant chose to be interviewed after participating in a classroom or individual orientation activity and brief explanation of the study. All potential study participants chose to be interviewed after the orientation activity. The orientation activity helped explain what the study was about, why it was important, and what would be expected of participants. Each participant was paid $\$ 10$ for each of the two 30-minute interviews. Of the 150, most were participants in group instruction or one-on-one instruction within a group setting. A small number were receiving one-onone instruction outside of a group setting. 
The study sample was not constructed to be representative of the entire national population of adult learners in ESOL, ABE, and ASE programs. Such a sample was outside the capacity of the study. The findings of this study, therefore, may not hold for the entire population or for specific sub-populations that are not represented in the study sample, or not represented in sufficient numbers.

All participants were receiving instruction at a pre-GED level, which indicated that they scored at a fifth to eighth grade reading level on the Test of Adult Basic Education (TABE) or were identified with other assessment instruments to be within this range. A single instructional level was chosen to limit the effects of variability in student characteristics that is common to adult education populations. The study team chose to limit this variability by concentrating data collection on a population that was in the middle of the range of instructional levels, which are typically described as grades 0-4, pre-GED, and GED. GED students were eliminated because many would have completed their tests and graduated before follow-up interviews, which were scheduled at least four months after the first interview, could take place. Students in the 0-4 level might be more likely to have severe learning disabilities. By focusing on the mid-range, the study team hoped to have findings that would be applicable to the widest group of participants.

Some students enrolled in the pre-GED classes were actually reading either below or above the pre-GED level. Reasons given for this included: Some students wanted to remain with a specific teacher instead of "moving up" into a GED class; there was no class at the lower or higher level available; and a student was ready to take the GED in all subjects except one (usually math or writing) and was placed in a pre-GED class to master that subject.

Three of the sites were located in community centers; three were part of a family literacy center; two were in homeless or drop-in shelters; one was in a career center; one was in a housing development; one was in a community college; and four were either part of or located within a public school building. All received state funds, which means that they were also, in part, supported by federal funds. Of the 15 sites, eight had students who lived in rural areas while seven had students who lived in urban areas. Thirteen of the classes took place during the day and six took place in the evening.

The study team was unsuccessful at locating workplace education classes that were at a pre-GED level. The workplace education programs that were contacted 
offered specialized training courses, GED classes, and ESOL classes. The study team also tried to include adult learners who were enrolled in a tutoring program such as those supported by Laubach Literacy and Literacy Volunteers of America, but the students that were identified were reading below the pre-GED level.

Each program received a three-page fact sheet about the study (see Appendix A). After reading the fact sheet, the teacher or program coordinator made a decision about whether or not to invite students to participate in the study. Before the first interview with participants took place, each class participated in an orientation activity (see Appendix B). The orientation had three objectives. The first objective was to start the study participants thinking about the forces that were supporting or hindering their persistence. The second objective was to explain the force-field analysis approach so that the study questions would make more sense to participants. The third objective was to build a friendly rapport between the students and the research team so that the interview could be relaxed, informal, and honest.

The orientation activity involved the study participants (either as a class or as individuals depending on their program type) in a force-field analysis of a goal other than persistence in learning. The participants chose the topics, which included losing weight, owning a home, getting off welfare, and quitting smoking. The participants first brainstormed positive and negative forces, and then the class was broken into two groups, one representing the positive forces and the other the negative forces. One class member played the person trying to make the decision and the two groups tried to convince him or her by speaking from the point of view of the force they were representing. At the end of the exercise, the person charged with making the decision gave his or her answer. The students then talked about the experience. Teachers and counselors were given the choice to observe, participate, or leave the room for the activity. Six teachers chose to observe, two chose to participate, eleven chose to leave the room.

The first interviews took place between early October and early December, 1997. Since there were only two interviewers, classes were visited over a period of six weeks. Some of the interviews, therefore, took place in the first few days of instruction and some took place after a few weeks of instruction. Federal and state funded programs do not count a participant as registered until he or she completes 12 hours of instruction, and some of the study participants were interviewed before 12 hours of instruction were completed. Some participants may have dropped out before the study team arrived. The overall persistence rate might be higher or lower than it would have 
been had all of the first interviews taken place between the 12th and 13th hours of instruction in every class.

In four of the six evening classes, where time was more limited than the day classes, teachers and students were unwilling to give up their class time for the orientation activity. In those cases, the teachers and students agreed on an alternative to save time. Instead of taking 35 minutes of class time to do the force field activity, the interviewers used a shorter one-on-one version (see Appendix C) with each student just prior to the interview.

Two research assistants interviewed the study participants. One of the interviewers was a white woman in her late 20s, and the other interviewer was an African-American woman in her 40s. In some cases, the research assistants facilitated the orientation activity together, and this allowed students to choose an interviewer. Students were interviewed from 30 minutes to 7 days after the orientation activity, depending on the student's availability. One of the research assistants participated in the development of the interview protocols and instruments, including the field testing. She trained the second interviewer.

A one-on-one interview was chosen because of the literacy skill level of the students. The first part of the interview was structured to elicit specific information about the adult learners and their experience with education. When the interview turned to identification of the positive and negative forces, participants were asked to first list all of the important forces. After listing these, participants were asked to identify the three most important positive and negative forces.

To ensure that the interview protocols would employ appropriate language and content for adult learners, the study team asked 10 adult education teachers from the New England area to review them and give advice. The study team piloted the interview protocol with four learners in one pre-GED class. After the pilot, the protocol was revised based on feedback from the respondents, the teacher, and the program coordinator. The final interview form can be found in Appendix D.

Each interview took an average of 30 minutes to complete. The study team asked the teachers to determine the most convenient time to interview students. In most cases, students were interviewed during their scheduled class time. In some cases, students volunteered to stay after class and be interviewed then. At the beginning of the interview, study participants were asked to sign a permission form (see Appendix E), 
which asked for contact information to facilitate a follow-up interview. Responses to the interview questions were recorded on the interview form by the interviewer. Audiotaping was not done because it might have inhibited responses and the questionnaire required quite simple notes. However, the research team later realized that there were a few instances where it would have been helpful to listen to excerpts from audiotapes in order to capture a respondent's tone, to clarify something the interviewer wrote, or to obtain precise quotes.

Four months after the first interview, an attempt was made to contact each study participant. To ensure success in reaching learners, the following steps were taken.

- The interviewer contacted the programs and obtained information about which students were currently in classes, which students had left the program without completing their classes, and which students had graduated from the program.

- The interviewer then set a date and a time frame when she would be at the program conducting the interviews. Like the first interviews, they were done mostly during class hours with students who were still enrolled in the programs.

- For students who were no longer enrolled in programs, the interviewer contacted the students a week ahead of the scheduled visit and asked them if they would prefer to do the second interview on the phone or if they would like to come in to the program for the interview. She informed them that if the interview was conducted in person they would receive the agreed upon $\$ 10$ in cash. If the interview took place on the phone, a check would be mailed to them within 4 to 6 weeks.

- Where students chose to be interviewed by phone, the interviewer gave the option of either scheduling an interview time within the week or conducting the interview immediately. After several students did not keep their phone appointments, the interviewer asked students to do the interview immediately.

- Where students chose to be interviewed in-person, they met the interviewer at the learning center they used to attend. In one case, visiting the program for the interview became a catalyst for the student to re-enroll in the program. In other cases, students visited with their former teachers and classmates.

- For students still enrolled in classes, the interviewer asked the teacher to remind students of when they would be interviewed. Also, the night before a second interview, the interviewer gave each student a reminder call. The reminder call proved to be very successful. In many cases, at the time of the interview, students remarked on how considerate they thought it was to receive the call. In some 
cases, it helped to jog students' memories as to what they talked about in the first interview, which prepared them for the second interview. During the reminder call, some students who were not planning to attend class because of a work or family conflict made an appointment with the interviewer either before or after the class session hours.

- Every student (119) whom the interviewer was able to contact agreed to the second interview.

One of the two interviewers moved out of state, and, therefore, 90 percent of the second interviews were conducted by the remaining interviewer. When possible, interviews were completed in person. When in-person interviews were not possible, participants were contacted by phone. Unfortunately, many of the phone numbers of study participants had been disconnected or participants were no longer at the number they had given earlier. Homeless participants were especially difficult to reach. Dropouts were evenly distributed among the classes and, therefore, no site or class characteristics resulted in higher dropout. Three months after the four-month mark, the study team tried the disconnected numbers again, with some success. When contacted, two participants denied their identity and would not be interviewed. All together 119 (79\%) of the 150 students were contacted for the second interview. Of the 31 students who could not be reached, attempts to locate 17 participants resulted in no information. Their teachers and classmates could not or would not provide information about why they might have left the program.

Of the remaining 14, one student was in a correctional facility and unavailable for interview; one was homeless and not reachable; one was "released by the program after multiple performance and attendance issues;" one was expelled from the program because of "getting in the way of other students' progress;" one moved and was hiding from her husband; one was having problems with her daughter and had to make family her priority; one had relapsed into using drugs and had been removed from the half-way house she was staying at; one had been sick and disappeared from a program; one had serious health problems and could not answer the questions; two had gone back to work and this presented a conflict with class time; and for three, several phone messages were left with people at their house or on a machine but these were never returned.

Three coders worked on the data: the study director, the research assistant who collected the data, and a research assistant who worked on data analysis. The three coders developed the coding procedure together and tried it out several times to refine 
their coding procedures. Most of the answers were easy to code and to place within both the categories and subcategories of the analysis framework. In order to assure inter-rater reliability, the three coders worked in the same room and discussed any ambiguous answers. After the first coding, the research team discussed any possible biases they may have brought to the coding and, through this process of discussion, arrived at decisions on how to classify difficult to code responses. The coding difficulties were with placing answers within one of the categories or subcategories of forces.

\section{FINDINGS}

\section{Description of the Sample}

Demographics. Of the 150 subjects included in the study, 68.7 percent (103) were women. Almost two thirds of the subjects (64 percent/96) were white, 13.3 percent were African American, 12 percent were Hispanic, 2.8 percent were Haitian, and 7.3 percent (11) were non-Hispanic immigrants from countries that included Afghanistan, Cambodia, Jamaica, Hong Kong, Pakistan, and Portugal. Subjects ranged in age from 16 to 62 , with an average age of 34 . More than half the sample (58 percent/88) was between the ages of 21 and 39, and 13 percent (19) were between 16 and 20. Table 1 presents demographic data on the sample.

\section{Table 1 - Demographics of the Sample: Gender, Ethnicity, and Age}

\begin{tabular}{lccc}
\hline & Percentage of Sample & Number of Respondents & Percent Female \\
\hline \hline Gender & \multicolumn{3}{c}{} \\
\hline Female & 68.8 & 103 & - \\
Male & 31.3 & 47 & - \\
\hline Ethnicity & & & 65.6 \\
\hline White & 64.0 & 96 & 60.0 \\
African American & 13.3 & 20 & 100.0 \\
Hispanic & 12.0 & 18 & 50.0 \\
Haitian & 2.8 & 4 & 63.6 \\
Other ESOL & 7.3 & 11 & 100.0 \\
N/A & 0.7 & 1 & 57.9 \\
\hline Age Group & & & 84.2 \\
\hline 16 to 20 & 12.7 & 19 & 64.0 \\
21 to 29 & 25.3 & 38 & 65.5 \\
30 to 39 & 33.3 & 50 & 61.5 \\
40 to 49 & 19.3 & 29 & 100.0 \\
50 to 59 & 8.7 & 13 & \\
60 to 69 & 0.7 & 1 & \\
\hline
\end{tabular}


Note: The study included a total of 150 subjects.

Background Characteristics. Seventy percent (105) of the sample had children; approximately three quarters of this group were women. Thirty-eight percent (57) of the sample were single parents, 87 percent (50) of whom were women. A little more than one half of the sample (54.8 percent/82) were parents of young children or teens. With respect to employment, 43 percent of the sample (65) was employed outside the home, and 30 percent of the sample worked 40 hours or more per week. Table 2 provides additional data on parenting and work status.

Table 2 - Background Characteristics: Parenting and Employment Status

\begin{tabular}{|c|c|c|c|}
\hline & Percentage of Sample & Number of Respondents & Percent Female \\
\hline \multicolumn{4}{|l|}{ Parenting Status } \\
\hline Have Children & 70.0 & 105 & 76.2 \\
\hline No Children & 28.7 & 43 & 53.5 \\
\hline N/A & 1.3 & 2 & - \\
\hline Single Parents & 38.0 & 57 & 87.7 \\
\hline \multicolumn{4}{|l|}{ Parents of Young } \\
\hline Children or Teens & 54.7 & 82 & 81.7 \\
\hline \multicolumn{4}{|l|}{ Employment Status } \\
\hline Employed & 43.3 & 65 & 58.5 \\
\hline Unemployed & 55.3 & 83 & 75.9 \\
\hline Retired & 0.7 & 1 & 100.0 \\
\hline N/A & 0.7 & 1 & 100.0 \\
\hline \multicolumn{4}{|l|}{ Working Hours/Week } \\
\hline 1 to 10 & 1.3 & 2 & 100.0 \\
\hline 11 to 25 & 6.0 & 9 & 66.7 \\
\hline 26 to 39 & 6.7 & 10 & 80.0 \\
\hline 40 or more & 30.0 & 45 & 51.1 \\
\hline N/A & 56.0 & 84 & 76.2 \\
\hline
\end{tabular}

Note: The total number of subjects interviewed was 150,103 of whom were female.

Educational Background. As Table 3 shows, 86 percent (129) of the sample are school dropouts. The average age of dropout among subjects was 15.5 (s.d.= 3.19). The majority of dropouts (68.7 percent) left school between the ages of 15 and 18 , and nearly a quarter of dropouts (27.1 percent/36) occurred at eighth grade or earlier.

Table 3 - Educational Background

\begin{tabular}{lcc}
\hline Educational Background & Percentage of Sample & Number of Respondents \\
\hline \hline School dropout & 86.0 & 129 \\
U.S.-schooled & 84.7 & 127 \\
\hline
\end{tabular}


Subjects Schooled Outside of the U.S. Out of the sample of 150 learners, 15.3 percent (23) received their schooling outside of the United States. The school experience data for this group has been analyzed separately to see if the behavior of these foreign-educated respondents demonstrates any trends that would distinguish them from patterns of persistence shown among U.S.-schooled subjects. The two groups of learners differed on the average age of dropout from school, with an average of 16 (s.d.=1.94) for the U.S. group and 12.8 (s.d.=5.91) for the non-U.S. group. The mean grade at dropout was different for the two groups, with grade 9.6 (s.d. = 1.94) for the U.S. learners and grade 8.1 (s.d. = 4.12) for the non-U.S. learners. With respect to both measures, however, the non-U.S. group showed greater variability than did the U.S. group, which might be explained by the fact that they came from several different countries.

\section{Persistence in Pre-GED Studies}

At the time of the second interview, subjects in the study were rated as persisters if they were still attending their class, had transferred to another class or to self-study in preparation for the GED, or had met their goal of preparation for the GED. Of the 150 subjects, 67 percent (100) were rated as persisters. Of the total sample, 52 percent (78) were still attending their class, 6 percent (9) had transferred, and 9 percent (13) had met their goal of GED preparation. Dropouts, who constituted 33 percent (50) of the sample, included those who reported that they were no longer engaged in study and those who proved impossible to locate.

Two groups were problematic: those who reported a transfer to self-study and those who could not be contacted. The assignment of subjects to either of the two categories was not arbitrary. Most people who take the GED test never attend a class and, therefore, self-study preparation for the test is common. Assigning those who professed self-study to that category is probably accurate. Those who could not be contacted (21 percent/31) had all stopped coming to class, but some second-hand information was gathered about 14 of them. If that second-hand information is correct, all 14 would be classified as dropouts. Classifying all 31 as dropouts, therefore, is probably accurate.

\section{Persistence Rates Among Particular Groups}


In analyzing the relationship between persistence and the factors included in our study (i.e., learner background, educational experience, supports and obstacles), we performed a series of $\chi^{2}$ (chi square) tests to determine whether these factors had a statistically significant relationship to persistence. The reader should keep in mind that the relatively small size of our sample and the consequent small number of people falling into some categories may not allow us to observe significant relationships. If tested with larger samples, some of these relationships might prove to be statistically significant. Future studies of persistence might therefore explore relationships between persistence and learner characteristics and obtain different results.

Demographic Groups. With respect to demographic groups and persistence, men and women included in the study persisted at similar rates, 63.8 percent and 68.0 percent, respectively. The difference in these rates was not statistically significant. Although some differences were observed among ethnic groups, as can be seen in Table 4, these differences were not statistically significant. While gender and ethnicity did not prove to be significant predictors of persistence, age did show a relationship to persistence. As data in Table 5 show, subjects aged 30 and older persisted at higher rates than subjects in their teens or 20s. More than three quarters of subjects 30 years old and over persisted, compared with 52 and 40 percent of subjects in their 20s and teens. Differences across age groups were statistically significant at the .05 level $\left(\chi^{2}=\right.$ $17.17, \mathrm{p}=.004)$. The observed differences between groups younger and older than age 30 may be attributable to maturity and a clearer purpose for learning, reduced responsibilities of child-rearing, or the suitability of curriculum and instruction to the needs of older adults. More research is needed to better understand reasons for difference in persistence across age groups, since this might lead to advice for programs on how to serve younger groups better. 
Table 4 - Persistence Rates by Demographic Groups

\begin{tabular}{lcc}
\hline & Percent Persisted & Number Persisted/Total \\
\hline \hline Gender & & \\
\hline Female & 63.8 & $70 / 103$ \\
Male & 68.0 & $30 / 47$ \\
\hline Ethnicity & & \\
\hline White & 67.7 & $65 / 96$ \\
African-American & 55.0 & $11 / 55$ \\
Hispanic & 66.7 & $12 / 18$ \\
Haitian & 75.0 & $3 / 4$ \\
Other ESOL & 81.8 & $9 / 11$ \\
\hline Age Group & & $*$ \\
\hline 16 to 20 & 42.1 & $8 / 19$ \\
21 to 29 & 52.6 & $20 / 38$ \\
30 to 39 & 74.0 & $37 / 50$ \\
40 to 49 & 72.4 & $21 / 29$ \\
50 to 69 & 100.0 & $14 / 14$ \\
\hline
\end{tabular}

* Indicates a significant relationship with persistence, based on $\chi^{2}$ tests. $\mathrm{p}<.05$.

Parenting and Employment Status Factors. With respect to their parenting status, having children and, in particular, having older children, proved to be significant predictors of persistence. As data in Table 5 demonstrate, 71 percent of subjects with children persisted, compared to only 58 percent of subjects who did not have children. According to a $\chi^{2}$ test, this difference was significant at the .05 level $\left(\chi^{2}=6.48, p=.04\right)$. In addition, the age of children appeared to play a role in persistence. Parents with teenage and adult children persisted at rates of 83 percent and 91 percent, respectively, compared with 63 percent of subjects with young children. A $\chi^{2}$ test indicated that this difference was significant at the .05 level $\left(\chi^{2}=11.71, \mathrm{p}=.01\right)$. Status as a single parent did not prove to be a significant predictor of persistence. It may be that having children serves as a support to learner persistence as parents seek to pursue a better life for their families or serve as role models for their children. It may also be that older children provide encouragement and support to their parents as they participate in $\mathrm{ABE}$ programs, while younger children are demanding of time and act as a barrier to persistence. 
Table 5 - Persistence Rates by Parenting Status

\begin{tabular}{lcc}
\hline & Percent Persisted & Number Persisted/Total \\
\hline \hline Have Children & & $*$ \\
\hline Yes & 71.4 & $75 / 105$ \\
No & 58.1 & $25 / 43$ \\
\hline Age of Children & & $*$ \\
\hline Young & 62.5 & $40 / 64$ \\
Teenage & 83.3 & $15 / 18$ \\
Adult & 90.9 & $20 / 22$ \\
\hline Single Parent Status & & $39 / 57$ \\
Single & 68.4 & $24 / 35$ \\
Not Single & 68.6 & $37 / 58$ \\
N/A & 63.8 & \\
\hline
\end{tabular}

* Indicates a significant relationship with persistence, based on $\chi^{2}$ tests. $\mathrm{p}<.05$.

Employment status did not prove to be a significant predictor of persistence among subjects in the study. The difference in persistence rates between employed subjects (67.7 percent) and unemployed subjects (65.1 percent) was not significant. Like general employment status, working hours did not help to predict persistence. Subjects who worked 40 hours or more per week persisted at a rate of 64 percent, slightly below that of subjects working 11 to 25 hours (77.8 percent) and 26 to 39 hours (70 percent), but these differences were not significant.

Table 6 - Persistence Rates by Employment Status

\begin{tabular}{lcc}
\hline & Percent Persisted & Number Persisted/Total \\
\hline Employment Status & & \\
\hline Employed & 67.7 & $44 / 65$ \\
Unemployed & 65.1 & $54 / 83$ \\
Retired & 100.0 & $1 / 1$ \\
N/A & 100.0 & $1 / 1$ \\
\hline Working Hours/Week & & $2 / 2$ \\
\hline 1 to 10 & 100.0 & $7 / 9$ \\
11 to 25 & 77.8 & $7 / 10$ \\
26 to 39 & 70.0 & $29 / 45$ \\
40 or more & 64.0 & $55 / 84$ \\
N/A & 65.5 & 0 persistence.
\end{tabular}

Note: Based on $\chi^{2}$ tests, neither of these variables was a significant predictor of persistence. 
School Experience and Persistence. One hypothesis the study sought to explore suggests that school experience is related to learner persistence: negative school experiences might be associated with dropout and positive experience might be associated with persistence (Quigley, 1997). Negative school experience is probably not a negative force that most adults would mention, and, in fact, no study subjects identified past school experience as either a negative or positive force. One measure of school experience is whether or not a subject dropped out or completed high school. Among the 129 high school dropouts in the study, 65.1 percent persisted, while the rate among those who had graduated from high school was 71.4 percent. This difference was not significant. Data on persistence and school dropout and completion are presented in Table 7.

To further explore the hypothesis that negative school experience might be associated with dropout, the study gathered information on learners' school experiences and matched it with whether or not they persisted over the course of the study. In an effort to assess subjects' perception of their school experience, the study employed several questions in order to develop different indicators of school experience.

Subjects were asked to rate their time in school on a scale from 1 to 5 , with 5 indicating a "very positive" experience, 1 a "very negative" one, and 3 a "neutral" experience. Among the 149 responses to this question, participant experience was almost evenly spread across the 5 possible outcomes. In addition, persistence rates across the ratings did not differ significantly. Subjects who rated their school experience as "very negative" persisted at a rate of 65.5 percent, while those who rated the experience as "neutral" persisted at a rate of 62.9 percent, and those who rated it "very positive" persisted at a rate of 75 percent. The average school experience rating among subjects who persisted was 3.1, very close to the average among non-persisters (2.9). Learners' overall rating of school experience does not appear to predict their persistence. Table 7 presents additional data on school experience and persistence.

In addition to providing an overall rating of their school experience, subjects were asked to indicate what aspects of the experience made school positive and negative for them. Their responses were coded as "school-related," "non schoolrelated," or "mixed." Out of 150 respondents, 62.7 percent (94) indicated that what was positive for them was school-related, such as liking specific subjects or teachers. Another 21.3 percent (32) of the subjects indicated that what made school positive was unrelated to schooling, such as social interaction with peers or involvement in sports and other activities. Sixteen percent (24) of respondents indicated that a combination of 
schooling and non-schooling-related factors made school a positive experience for them. Roughly two thirds (63) of subjects who said school-related factors made school positive persisted, compared with 56 percent (18) of those who noted that non-school factors made school positive. Among those respondents who had mixed reasons for why school was positive, 79.2 percent (19) persisted. The difference among these three groups was not statistically significant. Data on why school was positive and persistence rates can be found in Table 7 .

With respect to what was negative about school, 44.7 percent (67) of the study's subjects indicated that schooling-related factors, such as difficulty with specific subjects or negative interaction with teachers and administration, made school negative. Another 43.3 percent (65) of respondents indicated that what was negative about school was unrelated to schooling. Such non-school factors included problems at home that distracted students from school work; the need to work, which undermined students' progress at school; or an unpleasant climate at school due to the presence of bullies, drug use, or gangs. Twelve percent (18) of subjects indicated that a mixture of schooling and non-schooling related factors contributed to negative aspects of their school experience. Nearly the same percentage of subjects (roughly two thirds) persisted, regardless of whether or not subjects noted that school-related factors made school a negative experience. Of the respondents who indicated mixed reasons why school was negative, 72.2 percent (13) persisted. The character of what made school a negative experience for subjects was not a significant predictor of their persistence. Table 7 presents additional school experience data.

As a final indicator of subjects' school experience, the study asked why subjects had left school. Their responses were coded according to whether their reason for leaving school had been school-related, non-school-related or due to reasons that fell into both categories. Results showed that 64 percent (84) of respondents had left school for non-school-related reasons, 26 percent (34) had left for school-related reasons, and 10 percent (13) left for mixed reasons. Persistence rates among all three of these groups were nearly the same. Among those who left school for school-related reasons, 67.6 percent (23) persisted, compared with 65.5 percent (55) of the non school-related group and 69.2 percent (9) of the mixed reason group. Differences among these three groups were not significant.

Whether subjects brought negative, positive, or mixed impressions from their school experience did not make a difference in persistence rates in most cases. Notable exceptions occurred in several cases. Those who gave a very positive school 
experience rating on the Likert scale had a persistence rate that was higher than 75 percent, thereby partially supporting the hypothesis that school experience might be linked to persistence. Among learners who indicated non-school-related reasons for why school was positive (thereby implying that school itself was negative), the persistence rate was only 56.3 percent. Learners who had mixed reasons (school- and non-school-related) for the positive and negative nature of school had persistence rates of 79.2 percent and 72.2 percent, respectively. A report of negative school experience does not appear to be associated with dropout in this study.

Current realities, rather than past experience, may be more closely associated with whether or not learners persist in programs. Also, it may be the case that most people for whom school experience is a powerful negative force never enter programs or drop out in the first few days.

Table 7 - Educational Background Factors

\begin{tabular}{lcc}
\hline & $\begin{array}{c}\text { Percent } \\
\text { Persisted }\end{array}$ & $\begin{array}{c}\text { Number } \\
\text { Persisted/Total }\end{array}$ \\
\hline \hline School Completion & & \\
\hline Dropout & 65.9 & $85 / 129$ \\
HS Graduate & 71.4 & $15 / 21$ \\
\hline School Experience & & \\
\hline Very negative & 65.5 & $19 / 29$ \\
Negative & 66.7 & $18 / 27$ \\
Neutral & 62.9 & $22 / 35$ \\
Positive & 66.7 & $20 / 30$ \\
Very positive & 75.0 & $21 / 28$ \\
\hline Why School was Positive & & \\
\hline School-related & 67.0 & $18 / 32$ \\
Non school-related & 56.3 & $19 / 24$ \\
Mixed & 79.2 & $44 / 67$ \\
\hline Why School was Negative & & $43 / 65$ \\
\hline School-related & 65.7 & $13 / 18$ \\
Non-school-related & 66.2 & \\
Mixed & 72.2 & $64 / 84$ \\
\hline Reasons for Leaving School & & $10 / 13$ \\
\hline School-related & 67.6 & \\
Non-school-related & 65.5 & \\
Mixed & 69.2 & \\
\hline Note: Based on $\chi^{2}$ tests, none of these factors had a significant relationship with persistence at the \\
05 level. & & \\
\hline
\end{tabular}


Non-U.S.-Schooled Subjects. While the study had not aimed at analyzing the behavior of ESOL students in particular, some interesting findings were observed among subjects schooled outside the U.S. that merit reporting. Overall, non-U.S. learners persisted at a higher rate, 82.6 percent, than did U.S.-schooled learners, at 63.5 percent. The difference between the U.S.-schooled and non-U.S.-schooled groups was not significant at the .05 level $\left(\chi^{2}=3.12, p=.08\right)$, but with a larger sample of non-U.S.-schooled subjects, the difference between groups might prove to be statistically significant.

The difference between U.S.- schooled and non-U.S.-schooled subjects can also be seen when looking at individual measures of school experience across the two groups. As shown in Table 8, among non-U.S. subjects who rated their school experience as 4 ("positive") and 5 ("very positive"), 85.7 percent (6) and 92.3 percent (12), respectively, persisted. Moreover, based on $\chi^{2}$ tests, among non-US schooled subjects, school experience had a significant relationship with persistence $\chi^{2}=5.97$, $\mathrm{p}=.05$ ). By contrast, data in Table 9 shows that U.S. subjects with similar school experience ratings persisted at rates of 60.9 percent (14) and 60.0 percent (9), respectively. School experience was not a significant predictor of persistence among US-schooled subjects. Non-U.S. subjects who rated their school experience as a 3 ("neutral") persisted less (33.3 percent/1) than did U.S. subjects (65.6 percent/21), however, the small number of non-U.S. subjects in this category may make meaningful comparison difficult.

As noted before, non-U.S. subjects had left school early primarily for nonschool reasons. Data on reasons for leaving school are contained in Table 8 (non-U.S.schooled) and Table 9 (U.S.-schooled). Within this "non-school" reason group, 91.7 percent (11) of non-U.S. subjects persisted compared with only 61.1 percent (44) of the comparable U.S.-schooled group. Similarly, persistence rates were higher among non-U.S. learners than among U.S.-schooled subjects in all categories of reasons why school was negative, as can be seen in data displayed in Tables 8 and 9 . 
Table 8 - Educational Background Factors - Non-U.S.-Schooled Subjects

\begin{tabular}{|c|c|c|}
\hline & $\begin{array}{c}\text { Percent } \\
\text { Persisted } \\
\end{array}$ & $\begin{array}{c}\text { Number } \\
\text { Persisted }\end{array}$ \\
\hline \multicolumn{3}{|l|}{ School Completion } \\
\hline Dropout & 84.6 & $11 / 13$ \\
\hline HS Graduate & 80.0 & $8 / 10$ \\
\hline School Experience & & $*$ \\
\hline Very negative & - & - \\
\hline Negative & - & - \\
\hline Neutral & 33.3 & $1 / 3$ \\
\hline Positive & 85.7 & $6 / 7$ \\
\hline Very positive & 92.3 & $12 / 13$ \\
\hline Why School was Positive & & $*$ \\
\hline School-related & 92.9 & $13 / 14$ \\
\hline Non school-related & 25.0 & $1 / 4$ \\
\hline Mixed & 100.0 & $5 / 5$ \\
\hline \multicolumn{3}{|l|}{ Why School was Negative } \\
\hline School-related & 77.8 & $7 / 9$ \\
\hline Non school-related & 80.0 & $8 / 10$ \\
\hline Mixed & 100.0 & $4 / 4$ \\
\hline \multicolumn{3}{|l|}{ Reasons for Leaving School } \\
\hline School-related & - & $0 / 1$ \\
\hline Non school-related & 91.7 & $11 / 12$ \\
\hline Mixed & 80.0 & $8 / 10$ \\
\hline
\end{tabular}

* Indicates a significant relationship with persistence, based on $\chi^{2}$ tests. $\mathrm{p}<.05$.

Note: There were 23 non-U.S.-schooled subjects in the study.

Such a trend is repeated among the groups of subjects responding to why school was positive. Non-U.S.-schooled subjects who had identified school as positive for school-related reasons persisted at a rate of 92.9 percent (13), while 100 percent 
(5) of those who identified it as positive for mixed school and non-school reasons persisted. Non-U.S.-schooled subjects' assessment of why school was positive had a significant relationship with persistence $\left(\chi^{2}=11.32, \mathrm{p}=.003\right)$; however, among USschooled subjects, such a relationship was not significant. U.S.-schooled subjects persisted at rates of 62.5 percent (50) for those who identified school-related reasons and 73.7 percent (14) for those who sited mixed reasons. Non-U.S.-schooled learners persisted at a lower rate (25.0 percent/1) than U.S. learners (60.7 percent/17) did in the category of non-school reasons why school was positive. The limited number of non-U.S. subjects in this category renders comparison difficult.

As data in Tables 8 and 9 indicate, among U.S.-schooled subjects, school experience, as measured by any of the elements described here, did not prove to be a significant predictor of persistence, but school experience among non U.S.-schooled subjects showed a relationship to persistence. The pattern observed among non-U.S. subjects seems to support Quigley's theory that school experience has an impact on persistence. A separate study that focused on non-U.S.-schooled learners might help to uncover some of the dynamics that produce the higher persistence rate among learners who had positive school experiences.

Table 9 - Educational Background Factors - U.S.-Schooled Subjects

\begin{tabular}{lcc}
\hline & $\begin{array}{c}\text { Percent } \\
\text { Persisted }\end{array}$ & $\begin{array}{c}\text { Number } \\
\text { Persisted }\end{array}$ \\
\hline \hline School Completion & & \\
\hline Dropout & 63.8 & $74 / 116$ \\
HS Graduate & 63.6 & $7 / 11$ \\
\hline School Experience & & \\
\hline very negative & 65.5 & $19 / 29$ \\
Negative & 66.7 & $18 / 27$ \\
Neutral & 65.6 & $21 / 32$ \\
Positive & 60.9 & $14 / 23$ \\
very positive & 60.0 & $9 / 15$ \\
\hline Why School was Positive & & \\
\hline school-related & 62.5 & $50 / 80$ \\
non school-related & 60.7 & $17 / 28$ \\
Mixed & 73.7 & $14 / 19$ \\
\hline Why School was Negative & & $37 / 58$ \\
\hline school-related & 63.8 & $35 / 55$ \\
non school-related & 63.6 & $9 / 14$ \\
$\quad$ Mixed & 64.3 & $23 / 33$ \\
\hline Reasons for Leaving School & & $44 / 72$ \\
\hline school-related & 69.7 & \\
non school-related & 61.1 & \\
\hline
\end{tabular}


Mixed $\quad 69.2 \quad 9 / 13$ .05 level.

There were 127 U.S.-schooled subjects included in the study.

Other Adults in the Lives of Study Subjects. The experience of school is not the only factor that shapes an adult's attitudes about schooling. The experiences of important people in a child's or an adult's life can play a role in either reinforcing or mitigating negative impressions gained from his or her own experience. As an additional means of gaining insight into the impressions of school that adults bring to their adult basic education experience, the study collected data on the educational background of adults who were important in subjects' childhood, as well as those adults who play a significant role in their lives today. Study subjects were asked to indicate the educational background of the adults who were significant in their childhood and in their current lives. Significant adults' educational backgrounds were categorized as "dropout," "high school plus" (at least a high school degree), "mixed" (some adults were dropouts and some were high school plus), or "unknown."

Of the total sample, 36.7 percent (55) of subjects indicated that the significant adults in their childhood had dropped out of school; 29.3 percent (44) noted that the adults in their childhood had mixed educational backgrounds of dropout and high school plus status; 19.3 percent (29) stated that significant adults in their childhood had at least a high school education; and 14.7 percent (22) did not know the education level of important adults in their childhood. Data on the educational background of adults important in learners' childhood can be found in Table 10.

With respect to persistence patterns, the lowest persistence rate was that of subjects whose significant adults in childhood had a high school education or more, only 51.7 percent (15) of whom persisted. Subjects persisted at higher rates if their childhood significant adults were dropouts (67.3 percent/55), or if their educational backgrounds were unknown (68.2 percent/22). The highest persistence rate (72.7 percent/44) was among subjects with childhood significant adults who were of mixed backgrounds. Differences in the persistence rate among these groupings were not significant. Thus, the educational background of important adults in the childhood of learners does not appear to be a significant predictor of persistence. 
Table 10 - The Educational Background of Adults Important in Learners' Childhood

\begin{tabular}{|c|c|c|c|}
\hline $\begin{array}{l}\text { Educational Background of } \\
\text { Important Adults }\end{array}$ & $\begin{array}{l}\text { Percentage } \\
\text { of Sample }\end{array}$ & $\begin{array}{c}\text { Percent of } \\
\text { Learners Who } \\
\text { Persisted }\end{array}$ & $\begin{array}{c}\text { Number of } \\
\text { Learners } \\
\text { Who Persisted }\end{array}$ \\
\hline Dropout & 36.7 & 69.1 & $38 / 55$ \\
\hline Mixed Dropout/ High School or More & 29.3 & 72.7 & $32 / 44$ \\
\hline High School or More & 19.3 & 51.7 & $15 / 29$ \\
\hline Unknown & 14.7 & 68.2 & $15 / 22$ \\
\hline
\end{tabular}

Note: Based on $\chi^{2}$ tests, this variable did not show a significant relationship to persistence at the .05 level.

Looking at the educational background of adults important in learners' current lives, the study found that 13.3 percent (20) of learners noted that adults important in their current lives had dropped out of school. Among this group, 80 percent (16) persisted. Slightly more than 37 percent (56) of subjects noted that adults important in their current lives had mixed educational backgrounds, combining dropouts with those who had at least a high school education. Of this group, 67.9 percent persisted. Of the 27.3 percent (41) of those subjects whose important adults had at least a high school degree, 63.4 percent (26) persisted. Twenty-two percent (33) of subjects did not know the educational background of adults important in their lives. This group persisted at a 60.6 percent (20) rate. Data on the educational background of adults important in learners' current lives can be found in Table 11. Differences across these groups were not significant. Much like the educational background of adults important in learners' childhood, the educational background of adults important in learners' current lives does not appear to be associated with persistence.

Table 11 - The Educational Background of Adults Important in Learners' Current Lives

\begin{tabular}{lccc}
\hline Educational Background of & $\begin{array}{c}\text { Percent of } \\
\text { Important Adults }\end{array}$ & $\begin{array}{c}\text { Number of } \\
\text { Searners }\end{array}$ \\
\hline \hline Dropout & 13.3 & $\begin{array}{c}\text { Learners Who } \\
\text { Persisted }\end{array}$ & $\begin{array}{c}\text { Who Persisted } \\
\text { Mixed Dropout/ High School or More }\end{array}$ \\
High School or More & 37.3 & 67.9 & $16 / 20$ \\
Unknown & 27.3 & 63.4 & $38 / 56$ \\
\hline
\end{tabular}

Note: Based on $\chi^{2}$ tests, this variable did not show a significant relationship to persistence at the .05 level.

In considering the educational background of important adults in the lives of the study's subjects, slightly different patterns emerged among U.S.-schooled and non- 
U.S.-schooled subjects. As data in Tables 12 through 15 demonstrate, in nearly every instance, non-U.S. learners showed higher persistence rates than did U.S. learners, regardless of the educational background of the adults important in subjects' childhood or current lives. While roughly two thirds of U.S.-schooled subjects persisted, regardless of the educational background of important adults in their childhood, nonU.S.-schooled subjects persisted at higher rates of 100 percent (5) among those whose important adults had a mixed educational background, 90 percent (10) among those whose important adults were school dropouts, and 80 percent (4) among those subjects who did not know the educational background of adults important in their childhood. Differences among these three groups were only significant among non-U.S.-schooled subjects $\left(\chi^{2}=11.10, p=.01\right)$. This finding suggests, as did the earlier discussion of school experience, that the youthful experiences of adult learners outside the U.S. might have an impact on their persistence in ways that are different from the schooling and childhood experiences of adult learners educated in the U.S.

Table 12 - The Educational Background of Adults Important in Learners' Childhood - Non-U.S.-Schooled Subjects

\begin{tabular}{lcc}
\hline $\begin{array}{l}\text { Educational Background } \\
\text { of Important Adults * }\end{array}$ & $\begin{array}{c}\text { Percent of Learners } \\
\text { Who Persisted }\end{array}$ & $\begin{array}{c}\text { Number of Learners } \\
\text { Who Persisted }\end{array}$ \\
\hline \hline Dropout & 90.9 & $10 / 11$ \\
Mixed Dropout/ High School or More & 100.0 & $5 / 5$ \\
High School or More & - & $0 / 2$ \\
Unknown & 80.0 & $4 / 5$ \\
\hline * Based on $\chi^{2}$ tests, this variable showed a significant relationship to persistence at the .05 level.
\end{tabular}

Table 13 - The Educational Background of Adults Important in Learners' Childhood - U.S.-Schooled Subjects

\begin{tabular}{lcc}
\hline $\begin{array}{l}\text { Educational Background of } \\
\text { Important Adults }\end{array}$ & $\begin{array}{c}\text { Percent of Learners } \\
\text { Who Persisted }\end{array}$ & $\begin{array}{c}\text { Number of Learners } \\
\text { Who Persisted }\end{array}$ \\
\hline \hline Dropout & 63.6 & $28 / 44$ \\
Mixed Dropout/ High School or More & 69.2 & $27 / 39$ \\
High School or More & 55.6 & $15 / 27$ \\
Unknown & 64.7 & $11 / 17$ \\
\hline
\end{tabular}

Note: Based on $\chi^{2}$ tests, this variable did not show a significant relationship to persistence at the .05 level.

Considering the educational background of adults important in subjects' current lives, non-U.S.-schooled subjects again tended to persist at rates higher than those of U.S.-schooled subjects, as data in Tables 14 and 15 reveal. For instance, 100 percent of respondents who indicated that important adults in their current lives had dropped out (6) or had achieved at least a high school education (3) persisted. Among U.S.- 
schooled subjects in comparable categories, only 71.4 percent (10) and 60.5 percent (23) of subjects persisted. Similarly, three fourths of non-U.S.-schooled subjects whose important adults had mixed backgrounds persisted, compared with two thirds of U.S.-schooled subjects. The educational background of important adults in learners' current lives did not prove significant for either U.S.-schooled or non-U.S.-schooled subjects.

Table 14 - The Educational Background of Adults Important in Learners' Current Lives- Non-U.S.-Schooled Subjects

\begin{tabular}{lcc}
\hline Educational Background of & $\begin{array}{c}\text { Percent of Learners } \\
\text { Who Persisted }\end{array}$ & $\begin{array}{c}\text { Number of Learners } \\
\text { Who Persisted }\end{array}$ \\
\hline \hline Dropout & 100.0 & $6 / 6$ \\
Mixed Dropout/ High School or More & 75.0 & $6 / 8$ \\
High School or More & 100.0 & $3 / 3$ \\
Unknown & 66.7 & $4 / 6$ \\
\hline
\end{tabular}

Note: Based on $\chi^{2}$ tests, this variable did not show a significant relationship to persistence at the .05 level.

Table 15 - The Educational Background of Adults Important in Learners' Current Lives - U.S.-Schooled Subjects

\begin{tabular}{lcc}
\hline $\begin{array}{l}\text { Educational Background of } \\
\text { Important Adults }\end{array}$ & $\begin{array}{c}\text { Percent of Learners } \\
\text { that Persisted }\end{array}$ & $\begin{array}{c}\text { Number of Learners } \\
\text { That Persisted }\end{array}$ \\
\hline \hline Dropout & 71.4 & $10 / 14$ \\
Mixed Dropout/ High School or More & 66.7 & $32 / 48$ \\
High School or More & 60.5 & $23 / 38$ \\
Unknown & 59.3 & $16 / 27$ \\
\hline
\end{tabular}

Note: Based on $\chi^{2}$ tests, this variable did not show a significant relationship to persistence at the .05 level.

One interesting finding of the study emerged from the unsolicited comments made by several subjects about the pursuit of adult learning by people close to them. Of the 150 respondents, 22.0 percent (33) noted that a spouse, child, or parent had previously, or was currently, pursuing a GED, a college degree, or another form of adult education. Of this group of 33, 70 percent (21) persisted in their own learning. There was no significant relationship between persistence and whether or not subjects indicated that a family member had participated in adult education. Since no question was asked about adult education experience among friends and family, nothing definitive can be said about this finding, but the presence of successful role models that come from the social circles of learners might provide additional support in helping to sustain motivation and promote persistence. The study's measures of previous schooling and attitudes about education may not be sufficient to reveal such relationships. 
The identification of this sub-group of adult students, even though the question was not asked, may indicate that successful adult learners encourage their friends and family to join and persist in education programs. This would be consistent with the findings of Bandura (1986) as he explored ways to enhance people's self-efficacy and change their behavior. His work emphasized the importance of "supporters" who model "for others how to manage difficult situations, by demonstrating the values of perseverance, and by providing positive incentives and resources for efficacious coping." Successful adult education students who are part of the lives of subjects in this study may carry out the role of "supporter," thereby helping to increase the likelihood of learner persistence.

Current and Prior Adult Learning Experiences. Subjects were asked about their current and previous adult learning experiences. Learners' average length of participation in their current programs was 10.8 months (s.d. $=21.08)$ with some individuals having attended programs less than one month, and some individuals having had a much longer connection to a program, including one woman with a 15-year history with her program. The majority of subjects in the study were relatively new to their programs at the time of the first round of interviews. Of the total sample, 66.7 percent (100) had been with their program 0 to 6 months. Another 20 percent (30) had been with their current program between 7 months and 2 years, and 6.7 percent (10) had been with a program 2 to 3 years. Only 6.0 percent (9) of learners had a history of more than 3 years with their current program.

As data in Table 16 show, persistence rates were similar for the subjects interviewed during their first 6 months of current program participation, but as a group, the persistence rate of these "new" learners was lower than the whole sample. Among subjects who were enrolled in their program 6 months or less, the persistence rate was 58 percent. Persistence rates were higher among learners who had been with their programs 7 months to 2 years ( 83.3 percent) and 2 to 3 (90.0 percent). Subjects who had been with their current program more than 36 months had persistence rates of 77.8 percent. These data suggest that, as learners in this sample establish a connection to a program, their likelihood of persisting might increase. The length of time in current adult education programs did not, however, prove to be a significant predictor of persistence. 
Table 16 - Time Spent in Current Program

\begin{tabular}{lccc}
\hline $\begin{array}{l}\text { Length of Time in } \\
\text { Program }\end{array}$ & $\begin{array}{c}\text { Percent of Total } \\
\text { Sample }\end{array}$ & $\begin{array}{c}\text { Percent of } \\
\text { Learners Who } \\
\text { Persisted }\end{array}$ & $\begin{array}{c}\text { Number of Learners } \\
\text { Who Persisted }\end{array}$ \\
\hline \hline 6 months or less & 66.7 & 58.0 & $58 / 100$ \\
7 months to 2 years & 20.0 & 83.3 & $25 / 30$ \\
2 to 3 years & 6.7 & 90.0 & $9 / 10$ \\
More than 3 years & 6.0 & 77.8 & $7 / 9$ \\
\hline
\end{tabular}

Note: Based on $\chi^{2}$ tests, this variable did not show a significant relationship to persistence at the .05 level. 149 responses were available regarding participant time spent in current programs.

Based on a Likert scale rating of 1 to 5 , study subjects indicated a highly positive view of their current program experience: 97.3 percent (146) rated their experience as "positive" or "very positive," and only 2.0 percent (3) rated their experience as either "neutral" or "negative." One learner gave no rating. Of the 146 who felt positive, 65.1 percent (95) persisted, and all three of the learners who had felt negatively about their experience persisted. The small number of learners who expressed unfavorable reactions to their experience make it difficult to compare persistence results between the two groups. The difference in persistence among the different rating groups did not prove to be statistically significant.

With respect to previous adult learning experiences, subjects were asked to comment on the frequency of prior $\mathrm{ABE}$ experience, self-study, and other types of non$\mathrm{ABE}$ formal learning experience. $\mathrm{ABE}$ experience included participation in pre-GED, GED, ESOL, or other basic skills programs, while non-ABE experience included vocational or technical training experiences. Self-study experiences were coded as follows: "yes" if subjects engaged in some structured, regular form of individual study, such as using a GED study guide to prepare for the test; "no" if subjects noted no effort at learning outside of a classroom or program context; and "some" if subjects indicated some type of activity that involved learning, such as visits to the library, frequent reading of newspapers, or forms of writing practice, with the aim of increasing their knowledge or skills.

Results indicate that 42.0 percent (63) of the 150 learners in the study had no prior ABE experience, 38.7 percent (58) had made one prior attempt, 14.0 percent (21) had made two attempts, and 5.3 percent (8) three attempts. As noted in Table 17 below, 61.9 percent (39) of the 63 learners without prior experience persisted, compared with 69.0 percent (40 of 58) of those who had made one previous attempt at ABE. Persistence was highest at 85.7 percent among those learners who had made 
two prior attempts, however the persistence rate among the eight learners who had made three prior attempts was only 37.50 percent. The relationship between prior experience in $\mathrm{ABE}$ and persistence was not significant. Table 17 presents data on prior $\mathrm{ABE}$ experience.

Table 17 - Prior ABE Experience

\begin{tabular}{lccc}
\hline ABE Experience & $\begin{array}{c}\text { Percent of total } \\
\text { sample }\end{array}$ & $\begin{array}{c}\text { Percent of learners } \\
\text { Who persisted }\end{array}$ & $\begin{array}{c}\text { Number of } \\
\text { Learners Who } \\
\text { Persisted }\end{array}$ \\
\hline \hline No ABE & 42.0 & 61.9 & $39 / 63$ \\
1 attempt & 38.7 & 69.0 & $40 / 58$ \\
2 attempts & 14.0 & 85.7 & $18 / 21$ \\
3 attempts & 5.3 & 37.5 & $3 / 8$ \\
\hline
\end{tabular}

Subjects' responses regarding their prior non-ABE program experiences showed that 86 percent (129) of subjects had no non-ABE program experience; 9.3 percent (14) had made one prior attempt; 2 percent (3) had made two attempts; 1.3 percent (2) made three attempts; and less than 1 percent made either four or five attempts. Whether or not subjects had prior non-ABE experience did not seem to greatly affect their persistence rates. Of the 129 learners that had no prior non-ABE adult learning experience, 67.4 percent (87) persisted, compared with 61.9 percent (13) of the combined 21 learners who had made from one to five previous non-ABE attempts. Persistence rates for each category of non-ABE experience are listed in Table 18 below. Differences in persistence among the categories of non-ABE experience were not statistically significant.

Table 18 - Prior Non-ABE Adult Learning Experience

\begin{tabular}{lccc}
\hline $\begin{array}{l}\text { Non-ABE } \\
\text { Experience }\end{array}$ & $\begin{array}{c}\text { Percent of total } \\
\text { sample }\end{array}$ & $\begin{array}{c}\text { Percent of learners } \\
\text { Who persisted }\end{array}$ & $\begin{array}{c}\text { Number Who } \\
\text { Persisted }\end{array}$ \\
\hline \hline None & 86.0 & 67.4 & $87 / 129$ \\
1 attempt & 9.3 & 57.1 & $8 / 14$ \\
2 attempts & 2.0 & 66.7 & $2 / 3$ \\
3 attempts & 1.3 & 50.0 & $1 / 2$ \\
4 attempts & 0.7 & 100.0 & $1 / 1$ \\
5 attempts & 0.7 & 100.0 & $1 / 1$ \\
\hline
\end{tabular}


Note: Based on $\chi^{2}$ tests, this variable did not show a significant relationship to persistence at the .05 level.

With respect to their experience of self-study, 13.3 percent (20) of subjects indicated that they had experience with structured self-study; 25.3 percent (38) had made some effort at individual learning; and 52.0 percent (78) of learners indicated that they had no self-study experience. Subjects who noted some prior effort at self-study tended to persist more often than those who did not. Data contained in Table 19 show that 75 percent (15) of those who had a regular, structured experience with self-study and 81.6 percent (31) of those with some self-study background persisted, compared to 57.7 percent (45) of learners who indicated no self-study experience. These differences were not significant at the .05 level $\left(\chi^{2}=7.29, \mathrm{p}=.06\right)$. In a larger sample size, however, this relationship might prove significant.

Table 19 - Prior Self-study Experience

\begin{tabular}{lccc}
\hline $\begin{array}{l}\text { Self-Study } \\
\text { Experience }\end{array}$ & $\begin{array}{c}\text { Percent of total } \\
\text { sample }\end{array}$ & $\begin{array}{c}\text { Percent of } \\
\text { Learners Who } \\
\text { Persisted }\end{array}$ & $\begin{array}{c}\text { Number of } \\
\text { Learners Who } \\
\text { Persisted }\end{array}$ \\
\hline \hline Yes & 13.3 & 75.0 & $15 / 20$ \\
No & 52.0 & 57.7 & $45 / 78$ \\
Some activity & 25.3 & 81.6 & $31 / 38$ \\
N/A & 9.3 & 64.3 & $9 / 14$ \\
\hline
\end{tabular}

Note: Based on $\chi^{2}$ tests, this variable did not show a significant relationship to persistence at the .05 level.

As noted above, previous adult learning experience was considered three different ways: prior participation in $\mathrm{ABE}$ programs, non- $\mathrm{ABE}$ adult learning programs, and individual study. When each type of learning experience is considered separately, persistence data for subjects seem to suggest that experience related to $\mathrm{ABE}$, ESOL, or GED learning (either program experience or self-study) is associated with persistence, but that non-academic learning is not. When grouped together, experience with the three forms of adult learning shows a more consistent trend. As the data displayed in Table 20 indicate, 50 percent (75) of subjects had one form of previous learning experience; 28.7 percent (43) had experience with two types of learning; only 1.3 percent (2) had experience with all three forms; and 20 percent (30) had no previous experience with $\mathrm{ABE}$, non-ABE classes, or self-study. With more adult learning experiences, persistence was higher among $\mathrm{ABE}$ learners. Of the total sample, 56.7 percent (17) of those with no prior experience persisted, compared with 62.7 percent (47) of those with one form of experience, and 81.4 percent (35) of those with two 
forms of experience. As learners gain more types of educational experiences, they may persist at higher rates. Since there are only two learners in the category of three experiences, the 50 percent figure may not be accurate. Differences in persistence rate among learners in each category were not statistically significant.

Table 20 - Forms of Adult Learning Experience

\begin{tabular}{ccc}
\hline $\begin{array}{c}\text { Number of Adult } \\
\text { Learning Experiences }\end{array}$ & $\begin{array}{c}\text { Percent of Learners Who } \\
\text { Persisted }\end{array}$ & $\begin{array}{c}\text { Number of Learners Who } \\
\text { Persisted }\end{array}$ \\
\hline \hline 0 & 56.7 & $17 / 30$ \\
1 & 62.7 & $47 / 75$ \\
2 & 81.4 & $35 / 43$ \\
3 & 50.0 & $1 / 2$ \\
\hline
\end{tabular}

Note: Based on $\chi^{2}$ tests, this variable did not show a significant relationship to persistence at the .05 level.

Subjects in the study were asked to indicate a reason for entering their current ABE programs. Since many responses actually contained more than one reason for entering, up to three reasons were noted for each respondent. Among the 150 learners, results were as follows: 45.3 percent (68) indicated the pursuit of their GED, adult diploma, or the acquisition of reading and writing skills as a reason for entering; 32.7 percent (49) indicated a work-related goal (e.g., to pursue a particular type of position or better job); 29.3 percent (44) gave a non-goal-oriented response (e.g., convenience of program location and time); 25.3 percent (38) indicated an individual goal (e.g., selfimprovement); 15.3 percent (23) indicated the goal of additional training or further education as a reason for entering (e.g., technical training or college); 10.7 percent (16) gave a family-related goal as their reason for entering (e.g., to help their children); and 6 percent (9) said they were in a program as a means toward attaining citizenship, including learning English as a second language. Table 21 below provides persistence and dropout rates for learners who indicated the reasons for entering noted above.

\section{Table 21 - Learner Persistence and Reasons for Entering ABE Programs}

\begin{tabular}{|c|c|c|c|}
\hline $\begin{array}{l}\text { Reason for Entering } \\
\text { ABE Program* }\end{array}$ & $\begin{array}{l}\text { Percent of } \\
\text { Sample }\end{array}$ & $\begin{array}{l}\text { Percent of } \\
\text { Learners Who } \\
\text { Persisted }\end{array}$ & $\begin{array}{c}\text { Number of } \\
\text { Learners Who } \\
\text { Persisted }\end{array}$ \\
\hline Individual Goal & 25.3 & 63.2 & $24 / 38$ \\
\hline Work-related Goal & 32.7 & 77.6 & $38 / 49$ \\
\hline Family-related Goal & 10.6 & 75.0 & $12 / 16$ \\
\hline Citizenship Goal & 6.0 & 77.8 & $7 / 9$ \\
\hline GED/ADP/ R\&W & 45.3 & 70.6 & $48 / 68$ \\
\hline
\end{tabular}


$\begin{array}{llll}\text { Training/further education } & 15.3 & 73.9 & 17 / 23\end{array}$

$\begin{array}{llll}\text { Non-goal Response } & 29.3 & 63.6 & 28 / 44\end{array}$

*Based on $\chi^{2}$ tests, this variable showed a significant relationship to persistence at the .05 level.

Among the study's respondents, 69.3 percent (104) indicated a specific goal related to work, family, citizenship, obtaining a GED or ADP, improving literacy skills, or preparing for training or further education. Of this group that identified specific goals, 72.1 percent (75) persisted. Among the remaining 30.7 percent (46) of subjects who did not identify a specific goal, only 54.3 percent (25) persisted. The difference between these two groups was significant $\left(\chi^{2}=4.53, p=.03\right)$. This finding suggests that learners with clearly defined goals will have a greater chance of persisting in their participation in $\mathrm{ABE}$ programs.

\section{Supports and Obstacles}

Each respondent in the study was asked to identify at least three supports and three obstacles encountered in their effort to persist at coming to the program. All subjects provided responses. As a follow-up question, subjects were asked to rank their supports and obstacles in order of importance; their top three choices were recorded and entered into the analysis. Responses were initially organized into the four areas described in the introduction: personal factors, life context factors, instructional factors, and program factors. Within each of these four categories, additional types of factors were identified. The percentages of subjects identifying particular supports and obstacles are listed in Tables 22 and 23 below.

As shown in Table 22, four types of supports were frequently noted by subjects in the study: relationships, goals, teacher/students, and positive self. Relationships, identified by 63.3 percent (95) of subjects, incorporates the support noted by subjects derived from their families, friends or colleagues, God or their church community, support groups, community workers, mentors or bosses, and their children. The next most frequently noted category of supports was goals, noted among 57.3 percent (86) of subjects. The goals included helping one's children, getting a better job, bettering one's self, "moving ahead" in life, attending college or some other academic goal, proving someone wrong, and obtaining citizenship. The third most frequent category of support was teacher/students, noted by 50.7 percent (76) of subjects. In this study, the category included references to the individual teacher (81 percent), fellow students ( 9 percent), or a combination of the two (10 percent). The fourth most frequently 
identified support was "positive self" noted by 44 percent (66) of subjects. This category included comments such as "it's me," "myself," or "my determination."

Other support categories that were less frequently mentioned included process orientation (8.7 percent/13), which comprised enjoyment of learning, skill achievement and routine/structure of learning in a program; life supports, noted in 7.3 percent (11) of cases, which included child care, conditions at home, mandatory participation in a program, work schedules, pleasure in being in the U.S., and subjects' own investment in class. Program-related factors were noted as supports by 8 percent (12) of subjects. Program factors included facilities and structure of programs, as well as overall program quality and program counselors. Instruction was the least frequently noted category of support, identified by only 3.3 percent (5) of subjects. This category comprised curriculum and methods, specific subjects and access to computers.

With respect to persistence rates, in most cases approximately two thirds of learners persisted, including those who identified personal factors, relationships, learning process, and teacher as supports to their persistence. In two instances, subjects persisted at a higher rate: those who identified program factors ( 83.3 percent) and those who noted life supports (72.7 percent). Learners who identified instructional factors as supports persisted at a lower rate of 40 percent. The small number (5) of subjects who identified this support makes it difficult to evaluate the impact of this type of support. None of the categories, including the most frequently noted ones, proved to be statistically significant. Data on the frequency of supports and persistence is displayed in Table 22.

Table 22 - Supports: Frequency and Relationship to Persistence

\begin{tabular}{lccc} 
& Percent Identified & Percent Persisted & Number Persisted \\
Factor & & & \\
\hline \hline Personal Factors & 44.0 & 66.7 & $44 / 66$ \\
$\quad$ Positive Self & 57.3 & 68.6 & $59 / 86$ \\
$\quad$ Goals & & & \\
Life Context Factors & 7.3 & 72.7 & $8 / 11$ \\
$\quad$ Life Supports &
\end{tabular}




\begin{tabular}{lccc}
\hline Relationships & 63.3 & 67.4 & $64 / 95$ \\
Instructional Factors & & & \\
Learning Process & 8.7 & 61.5 & $8 / 13$ \\
Teacher/Students & 50.7 & 68.4 & $52 / 76$ \\
Instruction & 3.3 & 40.0 & $2 / 5$ \\
Program Factors & & & \\
Program & 8.0 & 83.3 & $10 / 12$ \\
\hline
\end{tabular}

Note: Based on $\chi^{2}$ tests, these variables did not show a significant relationship to persistence at the .05 level.

With respect to negative forces, the most frequent category of obstacles was that of life demands, which was identified by 48.7 percent (73) of respondents. This category comprised conditions at home, special child care needs, work demands, transportation, own/family's health, age, lack of time/being fatigued, weather, welfare and other official rules, unfavorable conditions at home, moving and lack of income.

The next most frequent category of obstacle is relationships, noted by 16.7 percent (25) of subjects. These relationships included those with unsupportive family members, friends, or colleagues; community or welfare workers; religious beliefs; and fears about letting other people down by failing in a program.

Unlike the prevalence of positive self as a support, negative self was noted as an obstacle by only 11.3 (17) percent of subjects. Responses coded as "Negative Self" included comments such as "thinking negative thoughts," "my own laziness," and statements indicating a lack of subjects' confidence in their ability to succeed.

Instructional and program factors were noted least frequently among all obstacle categories. Only 8 percent (12) of subjects noted the learning process as an obstacle, while 6.7 percent (10) identified instructional factors as obstacles. A mere 2 percent (3) of subjects noted the teacher as an obstacle, and only 1.3 percent (2) of subjects identified program factors as obstacles. None of the relationships were significant. Data on the frequency of obstacles and persistence is displayed in Table 23.

Table 23 -Obstacles: Frequency and Relationship to Persistence

\begin{tabular}{lccc} 
Factor & Percent Identified & Percent Persisted & Number persisted \\
\hline \hline $\begin{array}{l}\text { Personal Factors } \\
\text { Negative Self }\end{array}$ & 11.3 & 70.6 & $12 / 17$ \\
Life Context Factors & & & \\
\hline
\end{tabular}




\begin{tabular}{lccc}
\hline Life Demands & 48.7 & 67.1 & $49 / 73$ \\
Relationships & 16.7 & 60.0 & $15 / 25$ \\
Instructional Factors & & & \\
$\quad$ Learning Process & 8.0 & 83.3 & $10 / 12$ \\
Teacher & 2.0 & 100.0 & $3 / 3$ \\
$\quad$ Instruction & 6.7 & 70.0 & $7 / 10$ \\
Program Factors & & & \\
$\quad$ Program & 1.3 & 100.0 & $2 / 2$ \\
\hline
\end{tabular}

Note: Based on $\chi^{2}$ tests, these variables did not show a significant relationship to persistence at the .05 level.

\section{DISCUSSION OF THE FINDINGS}

This study found that the many ways in which we can classify adult students (by gender, ethnicity, age, employment status, number and age of children, previous school experience, and educational background of other adults in their lives) do not tell us much about how to help them persist in their education. The only significant findings were that immigrants, those over the age of 30 , and parents of teenage or grown children were more likely to persist than others in the study. The greater likelihood of persistence by immigrant students in ESOL classes is well documented (Young et al., 1994a), and the findings of this study suggest that this effect continues as immigrants learn English and move on to pre-GED programs. Grown children might encourage their parents to join and persist in a program. On the other hand, adults who are over 30 are more likely to have teenage or grown children than those under 30 . These findings might point to older students persisting longer because they benefit from the maturity that comes with age and they no longer have the responsibilities of caring for small children.

Importantly, school experience (among U.S.-schooled learners) does not appear to be associated with persistence. Of course, those potential subjects who are significantly affected by negative school experience may never enter a program, or may have dropped out before the research team arrived. The actual responses of many of the study's subjects do point to very negative school experiences, with most of the comments centered on high school. Respondents reported being ridiculed and even struck by teachers, bullied or intimidated by other students, told that they were stupid, and asked to leave school by administrators. Issues of class, race, and sexual orientation were key to the negative school experience for some, as well. Entering an adult education program may signal that a learner has overcome the negative school experience and is ready to restart his/her education. 
This study also supports NEAEP's finding that students who persist for a few months are more likely to persist for a longer period of time. In this study, those who had been in a program for more than 6 months were more likely to persist than those who had been studying for a shorter period of time, although this difference was not statistically significant. Although previous attempts at some form of adult learning did not show a significant association with persistence in this study, had we adopted a different value, such as .10, to assess significance, previous attempts at adult learning would have been considered significant. The most significant among the prior learning experiences was self-study focused on improving basic skills or studying for the GED.

Prior attempts at self-study may be an indication of strong motivation. Or some people may need several attempts at learning before they are ready to persist. Research that looks at these attempts might uncover factors that lead to later persistence or to permanent non-participation. Another line of inquiry might look at making self-study outside of class a part of instruction so that adult dropouts are ready to continue their learning when they do leave class. This self-study might make a return to classes more likely and the development of ways to document that self-study could provide a more realistic account of persistence.

How adults describe the positive and negative forces that affect them did not predict persistence, but this information is still valuable in that it gives practitioners input from adult students on what might be important. Adults in this study had much more to say about positive forces than about negative forces. Every study participant mentioned at least three positive forces, and many mentioned between four and eight. No study participant mentioned more than three negative forces; most mentioned only one, and some mentioned none. Adding this information to the finding that negative school experience was not associated with persistence points to a conclusion that building positive forces may be more critical to increasing persistence than is the removal of barriers. If this is so, then understanding which positive forces are most important is essential to a model that supports persistence. The most often mentioned positive forces cluster in four categories of goals, relationships, teachers/students, and positive self.

The most frequently mentioned positive support is relationships. Among the supportive relationships noted by respondents, the most frequent was family support, identified by 78.9 percent (75) of the 95 respondents who noted relational supports. The support that adult learners receive from their social networks often extends outside 
the family. Another 10.5 percent (10) noted friends and colleagues as important supports, and the remaining 10.6 percent of respondents noted relationships with God/church (10), support groups (2), community workers (5), or mentors/bosses (5) as supports.

Although the relationship between persistence and relational supports did not prove statistically significant in this case, the prevalence of family support as an element of what learners say helps sustain their efforts to persist in programs raises a possible subject for further research. The study's findings did show that persistence was associated with parenthood, namely, that respondents with older children were more likely to persist. Parents with teenage and adult children persisted at rates of 83 percent and 91 percent, respectively, compared with 63 percent of subjects with younger children. One hypothesis that arises out of this finding is that teenage and older children are a relational support to adult students, while younger children are a barrier unless acceptable child care is available.

Another of the two most often cited positive forces identified by this study was "goal orientation." Among the 150 subjects in the study, 57.3 percent (86) identified a goal as one of the three main forces supporting their participation in ABE programs. Of the 86 people who noted goals as supports, 37.2 percent (32) said that helping their children was one of their supports. The second most frequent goal expressed by subjects was that of getting a better job, noted by 27.9 percent (24) of the "goal group." The third most frequent goal in the first round was that of an academic goal, which was noted by 18.6 percent (16) of first-round subjects who identified goals. The next most frequently mentioned goal was that of bettering one's self, identified by 17.4 percent (15) of the "goal orientation group." The next most frequent goal was that of "moving ahead in life," which was noted by 11.6 percent (10) of the "goal group." The three least frequently mentioned goals in the interviews were those of attending college, noted by 5.8 percent (5) of respondents; proving someone wrong, noted by 3.5 percent (3); and citizenship, noted by 1.2 percent (1). ${ }^{2}$ Although the study did not find a statistically significant relationship between the identification of goals as a support and persistence, findings did show a significant relationship between having a specific goal as a reason for entering ABE programs and persistence. Thus, it seems that goals do play a role in learner persistence.

\footnotetext{
${ }^{2}$ Numbers here may total more than 86 , since some subjects listed more than one goal as a support.
} 
The summary of Beder's discussion of theories of motivation suggests that adult students are weighing the benefit of reaching their life goals against the cost of participating in the education that will help them achieve those goals. Any model that seeks to support persistence will have to incorporate an attention to the formation, understanding, and commitment to individual goals. Most adults have goals that relate to employment, helping children, or educational accomplishment, and all three of these are goals around which curriculum and materials already exist. Other goals, though not as frequent, may have the same power to support persistence. Defining, understanding, and focusing of goals for participation may help adults to persist.

Another support that was mentioned by half (50.7 percent/79) of the study subjects was teachers and fellow students. This is also a form of relational support, but located in the classroom rather than in families, work, and communities. Most study subjects who mentioned these factors made simple statements such as "my teacher" or "the other students in the class." "Teacher" could refer to teaching methods, but it is probably representative of human support similar to family and non-family support. If this is true, then human support from family, friends and other non-family people, teachers, and classmates is viewed by adults as key to their success in adult education. Any model that seeks to support persistence should foster human support within the classroom as well as outside of it.

The fourth positive force that was mentioned by a large number of subjects was "positive self." Responses were coded as positive self if respondents said such things as "me," "myself," "will power," "desire," "the decision to make a commitment," "my own motivation," "my self-confidence," "I know I have to," "I'm the only one who can do it," "within myself, wanting to accomplish it," or "willingness to try." Of the 155 subjects, 44.0 percent (66) noted "positive self" as a support. Learners are saying that their own determination and self-efficacy about this task is a key support. Any model of support for persistence must help adult learners come to an understanding that they can be successful at this effort.

Other positive supports were mentioned by only a few respondents. Forces related to the program, such as facilities, approach to education, and counselors, along with factors related to instruction, such as curriculum, materials, equipment, and methods, were not mentioned by many. This may mean that adults in these programs are not used to talking about these factors in the same way that they are about goals, family support, and self-determination. Another explanation might be that these factors 
come into play later in the cycle of persistence as adults overcome the barriers to their persistence and begin to focus on barriers to learning.

The only negative force, or obstacle, that was noted nearly as often as the four major positive forces was "life demands," which was mentioned by 48.7 percent of respondents. Of the 73 respondents who noted life demands as obstacles, 27.4 percent (20) noted their own health, 24.7 percent (18) noted a lack of time and fatigue, 13.7 percent (10) noted child care, 13.7 percent (10) noted transportation, 11.0 percent (8) noted family health or special children's needs, 9.6 percent (7) noted lack of income, 8.2 percent (6) noted work demands, 6.8 percent (5) noted welfare and other rules and regulations, 4.1 percent (3) noted weather, 2.7 percent (2) noted conditions at home, 2.7 percent (2) noted their age, and 1.4 percent (1) noted moving.

As noted, relatively few subjects noted obstacles. This may indicate that subjects who were managing such demands no longer identify these elements as obstacles to persistence. People who encounter these life demands but do not overcome such barriers may never enter programs. The wide range of specific factors under the category 'life demands' points to the individual nature of these forces. One adult might have childcare as an overwhelming negative force, while another might be childless but need transportation. This points to the need to help adults arrange supports for the many life demands that can keep them from persisting in their studies. Any model that seeks to support persistence must help each adult manage the life demands that are the strongest deterrents to their own persistence.

\section{LESSONS FROM PROGRAM PRACTICE}

Before presenting a model for supporting persistence, the study team sought to identify ways in which programs were addressing the need to help adults persist in their studies. Little literature exists that describes these efforts, but interviews with program staff provided some insights. These practitioners were identified through discussions with national leaders and through postings on adult education listservs. An independent discussion on the $\mathrm{NLA}^{3}$ listserv proved to be a source of program information, as well. No effort was made to verify whether or not these program interventions produced measurable increases in persistence. Practitioners who have significant experience with adult learners and work within the constraints of program funding developed these

\footnotetext{
${ }^{3}$ The National Literacy Advocacy listserv is archived at www.nifl.gov.
} 
program interventions. Their attempts, therefore, represent an informed opinion of what might work within the constraints of existing program structures and funding. These interventions fell into the four categories of intake, orientation, instruction, and program activities.

\section{Intake}

Intake is usually brief and takes place when a potential student makes an inquiry as to availability of instruction. This can take place over the phone or at the program. Some programs help potential learners look at their goals and the life demands that might stand in the way of their reaching those goals. Through this process, some potential students find that they must arrange such things as daycare or transportation before they begin their studies. Others find that the amount of work needed to reach their goal might be greater than they are now committed to undertake.

In one program, the adult who finds his or her goal too ambitious or who needs support services that are not readily available is counseled to wait and enter the program when he or she is ready. In the another, the program helps the adult to rethink his or her goal and make it more realistic or assists in securing the services needed to attend. Although most readers would prefer to take the latter course, many programs are underfunded in relation to the need in their community, and the former approach is an honest effort to target resources to those who are most likely to benefit. In a third program, teachers give sample lessons to incoming students. After the lesson is complete, the teacher and students talk about how the learners felt about being in a class as an adult and whether or not they could be successful in classes that employ the instructional approach used in the program. This gives adult students an opportunity to reflect on a real experience before making a commitment. For programs that use a nontraditional instructional approach, this activity gives potential students an opportunity to experience the approach and ask questions about it before committing to attend.

\section{Orientation}

Orientation is a longer process that takes place after an adult has registered for instruction and is sometimes combined with the first few weeks of instruction. In some programs, current or past students provide advice and answer questions for new students. These sessions help new students think through what they need to do to be successful, and the experienced students provide role models of people who have been 
able to persist in their learning. In some programs, these sessions provide an opportunity for potential students to express their concerns, fears, and doubts without program staff being present.

Other programs offer comprehensive two- to four-week orientations to students who would otherwise be on a waiting list. These orientations are structured to help adults think about the task they have committed to undertake and the problems they might encounter while studying. In other programs, individual teachers are responsible for acclimating students to the program during the first week of class. This acclimation may be a formal, structured part of their curriculum, but it is often informally woven into the first few weeks of instruction.

An example of a comprehensive orientation is provided by Grijalva (1991). This orientation serves as an alternative to more traditional assessment procedures. In this example, students work in small groups engaged in activities that explore learning strategies and interests, perceptions of learning (school history), and goals (short and long term). The students also participate in one-on-one advising and goal setting. In some cases the knowledge of a student's life history, interests, and short- and longterm goals leads to suggestions that she or he join another program that might better serve his or her needs.

\section{Instruction}

Specific activities that are targeted to improve persistence can be part of instruction as well. In one case, a teacher focused her efforts on creating a comfortable, open classroom environment where complex issues, such as domestic violence, could be addressed. The teacher remarked that, in her classroom, students become friends and serve as supports for each other. In another case, a teacher of an early morning class started making coffee and bringing in muffins to create an adult, less "school-like" environment. One student told her that knowing that a cup of coffee would be waiting helped her get out of bed and make the decision to continue coming to class. Another teacher elicits students' barriers to learning and then makes these issues an integral part of the curriculum. One teacher holds periodic one-on-one meetings with each student, focusing on helping students set, revisit, and revise their short and long-term goals. She said that this helps her students become continually aware of their on-going progress. One-on-one meetings are time intensive, but the teacher who incorporated them into her class has 15 hours of classroom time a week with her students. In another classroom, the teacher and students celebrated progress by holding parties once a month that 
included cake for everyone and a ceremony that awarded a certificate to each student who progressed a grade level in their studies.

Practitioners also expressed opinions on the kinds of instruction that are most likely to support persistence. This general advice fell into four categories. The first category was centered on building community in the classroom. As students get to know each other and form personal relationships, they help each other to learn and persist in their studies. The second category was related to the first but focused on whether or not the class had managed enrollment (where students are let into a class on an infrequent and planned basis) or employed open enrollment (where new students could enter at any time). Managed enrollment was deemed more likely to support persistence. The third category related to relevance of the curriculum to the students. When students chose the content that they use to learn and practice their reading, writing, math, and speaking, they are more likely to persist. The fourth was acknowledgment of progress. These comments came from programs that offer interim certificates of progress or other visible forms of achievement, which they believe support persistence.

\section{Program Activities}

This is a miscellaneous category for those activities that did not fit into intake, orientation, or instruction. One program reported tracking students who drop out by hiring current students to interview students who have left. This program tries to find students a month after they leave and again after 90 days. The program also tries to track some students one year and even three years after they leave the program. In the interviews, the current students ask what impact the program had on the lives of the people who left, what they liked and didn't like about the program, why they left, and what may help them come back, if they need to. The program staff use the findings from these interviews to change their instructional approach in ways that might help students be more successful.

Some programs employ successful past or current students as mentors for other students during the whole year, not just at orientation. In some cases these students provide this service as a volunteer and in other cases they are paid staff. Some programs have former adult students in the positions of counselor, teacher, and director. These hiring practices are sometimes based on a philosophy that programs should be staffed by people from the communities that they serve, but it is also believed to lead to longer student persistence. 


\section{CONCLUSIONS}

The definition of persistence and the ways in which it is measured need to be refined. Hours of instruction in class or in tutoring sessions alone are not an accurate measure of persistence and undervalue effective learning activities that should be encouraged. A wider definition of persistence would allow practitioners to focus on helping adults become persistent learners who use episodes of program participation as critical parts of a comprehensive learning strategy that employs technology, media, selfstudy, engagement in community efforts, and both formal and informal group activities.

For this expanded definition of persistence to become valued, it must be measurable. The field needs tools and procedures for collecting evidence of "time-ontask" that could be credited to a program. Some of this "time-on-task" might be spent in classes, some in tutoring sessions, and some in self-study through technology, media, or instructional materials. Other "time-on-task" measures might include increased time reading or reading of new, more challenging materials and engagement in community improvement efforts that require the use of English, literacy, and math skills. Ways to measure and validate these efforts and link them to a plan of learning developed within a program context would transform some dropouts into persistent learners who are not presently attending formal classes or tutoring sessions.

This expanded definition would require programs to think of the relationship to their students differently. Programs would need added resources to stay connected and serve adult students when they are not attending formal classes or tutoring sessions. With these added resources, programs could treat their students as long-term clients who will use a range of services, some provided by the program and some by other agencies, to achieve significant improvement in their skills.

Activities that are believed to support persistence (or that are eventually proved to support persistence), such as goal setting, should become part of the established curriculum, and measures of the accomplishment of these tasks should be valued outcomes of participation that are part of accountability systems. Using the expanded definition presented here, persistence itself should be an outcome that is measured as part of an accountability system. 
Status as an ESOL student, age over 30 years, having teenage or grown children, and a history of prior self-study efforts appear to predict longer persistence. This information does not help us much in identifying how to help these or other students persist in their education. The force-field analysis points to positive forces as a way to increase persistence, and both the literature and practitioner opinion suggests that the first few weeks of instruction is the critical time to begin a process that supports persistence. The literature review, the research presented here, and the experience of programs suggest four supports to persistence, which are presented below.

The first support to persistence is the establishment of a goal by the student. This process begins before an adult enters a program. An adult who could be classified as a potential ABE, ESOL, or ASE student experiences an event in his or her life that causes him or her to enter an educational program. That event might be something dramatic; for example, a well-paid worker might lose his or her job and find that he or she does not have the basic skills needed to qualify for a new job at a similar pay scale. That event might be less dramatic; for example, a parent may decide he or she needs more education when a first child begins school. That the event might be subtle; for example, a school dropout might have always felt the desire to study for the GED but when his or her children are older and need less attention, there is finally some free time available for education. This event provides potential adult students with goals they hope to accomplish by entering an ABE, ESOL, or ASE program. The staff of the educational program must help the potential adult student define his or her goal and understand the many instructional objectives that must be accomplished on the road to meeting that goal. Teachers must then use those student goals as the context for instruction. This effort must continue as instruction proceeds because goals may change.

The Equipped for the Future initiative (Stein, 1995) offers an approach to understanding and defining the educational objectives needed to reach the most common goals expressed by adults in this study. Other goal setting approaches might work as well. One powerful factor in favor of EFF is that it focuses on the broader purposes of education, which include the adult roles of worker, family member, and citizen. Goals related to both work and family are certainly the most common in this study, but other goals, such as EFF's category of citizenship, are especially important to some learners.

The focus on goals is important, but specific individual goals may be only part of the picture. In the portion of the study that asked specifically about why each adult 
entered a program, a chronological string of goals was common. That full string of goals included "get a GED, go to college, get a better job, and help my children." Some people mentioned all of these, and some just mentioned a few. Those who only said, "get a GED," might have added some of these other goals had they been prompted by a simple "Why?" Teachers should enter into a dialogue with each student that leads to a better understanding of goals by both of them. In addition, most of us are used to thinking about goals as individual, but goals can be defined by a class of students or by the community in which they live. For example, most students in a class might have transportation needs. A group activity might lead to ride sharing or a request to a public agency for transportation support.

The second support is self-efficacy. The educational program must help adult students build self-efficacy about reaching their goals. The term self-confidence is quite often used in adult education literature, but self-efficacy has a different definition. Selfconfidence is a global feeling of being able to accomplish most tasks. Self-efficacy is focused on a specific set of tasks and represents the feeling of being able to accomplish that set of tasks, which here is successful learning in ABE, ESOL, or ASE programs. Success in these programs may, in fact, increase self-confidence. Drawing on Bandura's advice on building self-efficacy (1986), adult education programs should provide the following experiences to their participants as a means toward building their self-efficacy:

- Mastery experiences are those that allow an adult to be successful in learning and to have authentic evidence of that success. This does not mean that instruction should be designed to produce only easy and constant success. Adults must also experience overcoming failure and eventually achieving success through a sustained effort, and instruction should help them develop this insight. Some programs take care to provide regular recognition of progress and celebrations of achievement. Others make sure that instruction provides opportunities for success early in program participation. These efforts provide learners with opportunities to experience success.

- Vicarious experiences are those that are provided by social models. Adult learners should come in contact with adults who are just like them and have succeeded in an ABE, ESOL, or GED class. These role models, both through the knowledge they share directly and the indirect teaching of their behavior, help adult students acquire the skills to manage the many demands of the learning task. Some programs employ successful present or past students as speakers during intake and 
orientation activities, while others recruit past learners to be counselors, teachers, and directors. These past students provide models of success.

- Social persuasion is support from teachers, staff, counselors, fellow students, family, and friends that reinforces self-efficacy. These verbal assurances are needed, in part, to overcome the negative self-efficacy about learning built during schooling. Most practitioners provide verbal assurances, but some programs encourage family members to provide this positive reinforcement as well. Some teachers take great care to develop a culture of support among students in their classes. These efforts ensure positive support for students.

- Addressing physiological and emotional states is help to students to deal with the tension, stress, and other negative emotional states that can result from poor selfefficacy and can also lead to low self-efficacy. Adult learners must be helped to perceive and interpret these feelings so that they do not affect their self-efficacy. Some practitioners feel uncomfortable with addressing the personal problems of their students, and all practitioners must acknowledge that they are not trained mental health professionals. Even so, many teachers use life histories and dialogue journals to help students identify the physical and mental health problems that can effect their learning. For example, adults with limited English proficiency are usually anxious about speaking in front of a class. A teacher can encourage the class to write about these feelings of anxiety and discuss ways to overcome them. The teacher can then help her students practice speaking even though they do have feelings of anxiety. Just the acknowledgment that life experiences affect learning can help diminish their negative effect.

Many orientation and instruction activities identified in the section of this report on learning from practice provide the experiences that Bandura has outlined. Bandura's theory of self-efficacy can act as a powerful framework within which programs can improve on the activities they have already undertaken.

The third support is management of the positive and negative forces that help and hinder persistence. Programs must help students develop an understanding of the negative and positive forces that affect their persistence. Building on that understanding, each student must make plans to manage these forces so that persistence is more likely. The plans that come out of such an exercise should include strategies for persistence when the forces that affect a peoples' lives cause them to drop out. These plans must be revised as adults persist in their studies and these forces change. 
The interviews with adult students paint a picture of forces that are different for each individual, but the interviews show that positive forces may be more important to persistence than negative forces. The strongest positive force mentioned by adult students was the support of their families, friends, teachers, and fellow students. Although a program might not be able to do much about a student's family or friends, teachers and program staff can make an effort to provide personal support and build supportive classroom environments. Spending instructional time and resources on making the educational experience into one that is pleasant and supportive for adults appears to be a good investment.

The force-field theory itself offers a tool for understanding and planning to manage these forces. Students can be encouraged to discuss their persistence in terms of the force-field and to build their plan from that discussion. As happens in some programs, staff must be open to having the outcome of this step be early dropout for students who, for any reason, are not ready to persist in their studies. If this is the outcome, adults should be helped to make a plan to prepare to return and be successful later, if at all possible.

The fourth support is progress toward reaching a goal. If the goal is important, then adult students must make progress toward reaching that goal, and they must be able to measure that progress. Programs must provide services of sufficient quality that students make progress, and programs must have assessment procedures that allow students to measure their own progress. Much of the recent interest in measuring progress has come from the need to build systems of program accountability. Helping students measure their own progress may reqire tools and methods that are not appropriate for accountability purposes.

Portfolio and authentic assessment approaches may have weaknesses in an accountability system but might be very useful for adults who want to measure their own progress. These kinds of assessments can be an integral part of an instructional approach. Accountability systems need measures that are easy to collect and quantify, and these may not be useful to students and difficult to integrate into instruction. Further research into assessment might produce a hybrid system that addresses both accountability and student needs and could lead to certification of progress that occurs more frequently than it does at present in most programs. Several levels of certification within a program may be helpful to student morale, but state-level or even national 
certification of achievement might make smaller increments of learner progress more meaningful and provide a range of goal steps.

\section{NEXT STEPS}

These four supports are more likely to be built if the policy makers who provide funding value them. This means that persistence must become a more important measure in program accountability, and funding agencies must provide the technical assistance and training needed for programs to put these supports in place.

Researchers must help to develop both better measures of and tools for measuring persistence and to identify when a support is of sufficient quality and when it is not. Policy makers should hold programs accountable for the quality of their intake, orientation, instruction, and program approaches that support persistence. A measure of "readiness to persist" might be developed to judge the impact of these services on individual learners, since actual persistence can be affected by forces outside of the control of programs.

The next step in this research is to observe how real programs use the description of these four supports to change practice. Out of these observations can come a comprehensive program model that is focused on improving persistence rates. That model should then be tested with a variety of populations so that its effectiveness can be assessed. The adults who participate should be sources of insight into what worked and what did not so that improvements can be made based on both the quantitative and qualitative data. 


\section{REFERENCES}

Bandura, A. (1986). Social foundations of thought and action: A social cognitive theory. Englewood Cliffs, NJ: Prentice-Hall.

Beder, H. (1980). Reaching the hard to reach through effective marketing. In G. Darkenwald (Ed.), Reaching the hard to reach in continuing education. San Francisco: Jossey-Bass.

Beder, H. (1986). The basic principles and concepts of marketing. In H. Beder (Ed.), Marketing continuing education programs. San Francisco: Jossey-Bass.

Beder, H. (1990). Reasons for nonparticipation in adult basic education. Adult Education Quarterly, 40(4).

Beder, H. (1991). Adult literacy: Issues for policy and practice. Malabar, FL: Krieger.

Beder, H. (1992, Winter). Nonparticipation in adult education. NCAL Connections, pp.4-5.

Beder, H. (1999). The outcomes and impacts of adult literacy education in the United States (NCSALL Reports \#6). Cambridge, MA: National Center for the Study of Adult Learning and Literacy, Harvard Graduate School of Education.

Beder, H., \& Valentine, T. (1987). Iowa's adult basic education students:

Descriptive profiles based on motivations, cognitive ability, and sociodemographic variables. Des Moines, IA: Iowa Department of Education.

Beder, H., \& Valentine, T. (1990). Motivational profiles of adult education students. Adult Education Quarterly, 40(2).

Benseman, J. (1989). The view from the other side of the educational door: Adult education from the perspective of people with low levels of schooling. ERIC Document Number ED 305433.

Bickerton, R., Comings, J., Shields, K., \& Waldron, S. (1995). A research agenda for adult basic education: Report of a delphi study. Boston: World Education. 
Blais, J., Duquette, A., \& Painchaud, G. (1989). Deterrents to women's participation in work-related educational activities. Adult Educatiion Quarterly, 39(4).

Boshier, R. (1971). Motivational orientations of adult education participants: A factor analytic exploration of Houle's Typology. Adult Education, 21(2).

Boshier, R. (1973). Educational participation and drop-out: A theoretical model. Adult Education, 23(4).

Boshier, R. (1977). Motivational orientations revisited: Life space motives and the educational participation scale. Adult Education Quarterly, 27(1).

Bova, B. (1985). Participation patterns of ABE students. Adult Literacy and Basic Education, 9(2).

Center for Applied Linguistics (CAL). (1998). Research agenda for adult ESOL. Washington DC: Author.

Cervero, R., \& Fitzpatrick, T. (1990). The enduring effects of family role and schooling on participation in adult education. American Journal of Education, 99(1).

Comings, J. (1995). Literacy Skill Retention in adult students in developing countries. International Journal of Educational Development, 15(1).

Condelli, L. \& Kutner, M. (1997). Developing a national outcome reporting system for the adult education program. Washington DC: U.S. Department of Education, Office of Vocational and Adult Education.

Cross, K. (1981). Adults as learners: Increasing participation and facilitating learning. San Francisco: Jossey-Bass.

Darkenwald, G. (1986). Adult literacy education: A review of the research and priorities for future inquiry. New York: Literacy Assistance Center.

Darkenwald, G., \& Merriam, S. (1982). Adult education: Foundations of practice. New York: Harper and Row. 
Darkenwald, G., \& Valentine, T. (1985). Factor structure of deterrents to participation. Adult Education Quarterly, 35(4).

Donnaruma, T., Cox, D., \& Beder, H. (1980). Success in a high school completion program and its relation to field dependence-independence. Adult Education, 30(4).

Elliot, B. (1998). Digest of Adult Education Statistics - 1998. Washington, DC: U.S. Department of Education, Office of Vocational and Adult Education.

Fingeret, A. (1983). Social networks: A new perspective on independence and illiterate adults. Adult Education Quarterly, 33(3).

Fingeret, A. (1985). North Carolina adult basic education evaluation 1985.

Raleigh, NC: North Carolina State University, Department of Adult and Community College Education.

Freire, P. (1970). Pedagogy of the oppressed. New York: Seabury.

Gilbert, D., Fisk, S., \& Lindzey, G. (1998). Handbook of Social Psychology Volume I (4th ed.). Oxford, UK: Oxford University Press.

Grijalva, O. (1991). Goal-based assessment: An exploration team approach. ERIC Document Number ED 363143.

Hayes, E. (1988). A typology of low-literate adults based on perceptions of deterrents to participation in adult basic education. Adult Education Quarterly, 39(1).

Hill, S. (1987). Trends in adult edcation 1969-1984. Washington, DC: Center for Education Statistics, U.S. Department of Education.

Houle, C. (1961). The inquiring mind. Madison, WI: University of Wisconsin Press.

Johnstone, W., \& Rivera, R. (1965). Volunteers for learning: A study of the educational pursuits of American adults. Chicago: Aldine Publishing Company.

Kambouri, M., \& Francis, H. (1994). Time to leave? Progression and drop out in basic skills programmes. ERIC Document Number ED 37732. 
Kirsch, I., Jungeblut, A., Jenkins, L., \& Kolstad, A. (1993). Adult literacy in America: A first look at the results of the national adult literacy survey. Washington, DC: U.S. Department of Education.

Knowles, M. (1970). The modern practice of adult education: Andragogy versus pedagogy. New York: Association Press.

Kotler, P. (1975). Marketing for nonprofit organizations. Englewood Cliffs, NJ: Prentice Hall.

Lewin, K. (1999). The complete social scientist: A Kurt Lewin reader (Martin Gold, Ed.). Washington, DC: American Psychological Association.

Martindale, C., \& Drake, J. (1989). Factor structure of deterrents to participation in off-duty adult education programs. Adult Education Quarterly, 39(2).

Merriam, S., \& Caffarella, R. (1991). Learning in adulthood: A comprehensive guide. San Francisco: Jossey-Bass.

Mezirow, J., Darkenwald, G., \& Knox, A. (1975). Last gamble on education. Washington, DC: Adult Education Association of the USA.

Miller, H. (1967). Participation of adults in education: A force-field analysis. Boston: Center for the Study of Liberal Education for Adults.

Mortimer, J., \& Simmons, R. (1978). Adult socialization. Annual Review of Sociology, 4 (421-454).

Murnane, R., \& Levy, F. (1996). Teaching the new basic skills. New York: Free Press.

National Center for Education Statistics (NCES). (1997) Digest of education statistics (NCES 98-015). Washington, DC: Author.

National Institute for Literacy (NIFL). (2000). A national research and development agenda for adult learning and literacy. Washington DC: Author.

NLA. (1998). discussions on listserv are archived at www.nifl.gov. 
Perin, D., \& Greenberg, D. (1993). Relationship between literacy gains and length of stay in a basic education program for health care workers. Adult Basic Education, $3(3)$.

Quigley, B. (1990). Hidden Logic: Reproduction and resistance in adult literacy and adult basic education. Adult Education Quarterly, 40(2).

Quigley, B. (1997). Rethinking literacy education: The critical need for practicebased change. San Francisco: Jossey-Bass.

Reder, S. (1995). Literacy, Education and Learning Disabilities. Philadelphia: National Center on Adult Literacy, University of Pennsylvania.

Reissman, R. (1962). The culturally deprived child. New York: HarperCollins.

Rubenson, K. (1977). Participation in recurrent education: A research review. Paper presented at the meeting of the National Delegates on Developments in Recurrent Education, Paris.

Scanlan, S., \& Darkenwald, G. (1984). Identifying deterrents to participation in continuing education. Adult Education Quarterly, 34(3).

Stein, S. (1995). Equipped for the future: a customer-driven vision for adult literacy and lifelong learning, Washington DC: National Institute for Literacy, U.S. Department of Education.

Sticht, T. (1982). Evaluation of the reading potential concept for marginally illiteracy adults. Alexandria, VA: Human Resources Research Organization.

Sticht, T., McDonald, B., \& Erickson, P. (1998, January). Passports to paradise: The struggle to teach and to learn on the margins of adult education. San Diego: Consortium for Workforce Education and Lifelong Learning (CWELL).

Tracy-Mumford, F. (1994). Student retention: Creating student success (NAEPDC Monograph Number Two). Washington DC: NAEPDC. 
Van Tilberg, E., \& DuBois, J. (1989). Literacy students' perceptions of successful participation in adult education: A cross-cultural approach through expectancy valence. A Paper presented at the 30th Annual Adult Education Research Conference, University of Wisconsin, Madison, April 27-29.

Venezky, R., \& Wagner, D. (1994). Supply and demand for literacy instruction in the United States (NCAL Technical Report TR 94-10). Philadelphia: National Center on Adult Literacy, University of Pennsylvania.

Wikelund, K., Reder, S., \& Hart-Landsberg, S. (1992). Expanding theories of adult literacy participation: A literature review (NCAL Technical Report TR 92-1). Philadelphia: National Center on Adult Literacy, University of Pennsylvania.

Willis, P. (1978). Learning to Labour. Guildford, Surrey, UK: Biddles, Ltd.

Witkin, H., Oitman, P., Raskin, E., \& Karp, S. (1971). A manual for the embedded figures tests. Palo Alto, CA: Consulting Psychologist Press.

Young, M., Fleischman, H., Fitzgerald, N., \& Morgan, M. (1994a). National evaluation of adult education programs: Patterns and predictors of client attendance. Arlington, VA: Development Associates.

Young, M., Fleischman, H., Fitzgerald, N., \& Morgan, M. (1994b). National evaluation of adult programs: Learner outcomes and program results. Arlington, VA: Development Associates. 


\section{APPENDIX A}

\section{LEARNER MOTIVATION STUDY: INFORMATION SHEET}

\section{What organization is sponsoring this research?}

The National Center for the Study of Adult Learning and Literacy (NCSALL) at the Harvard Graduate School of Education is conducting the study. The goal of NCSALL's research is to provide information that can be used to improve practice in programs that offer ABE, ESOL, and Pre-GED services.

\section{Who is on the research team?}

John Comings, Principal Investigator. John is the director of NCSALL. Before coming to HGSE, he spent 12 years as Vice President of World Education, a Boston non-profit agency that provides technical assistance and training, pursues research, and manages projects in adult education around the world. He served as the Director of SABES (State Literacy Resource Center) in Massachusetts, assisted in the designing of instructor training programs, and directed projects that focused on improving the teaching of both math and health in adult education programs. His research and writing have focused on the impact of adult literacy programs and the factors that lead to that impact in the U.S. and in Third World countries.

Andrea Parrella, Research Assistant. Andrea just completed her Ed.M focusing on Adult Education at the Harvard Graduate School of Education. Before that, she spent four years in ABE programs in the Boston area working as a teacher and as a coordinator. She worked as a teacher at Roxbury Community College, the Suffolk County House of Corrections, and the American Red Cross Workplace Education Project and as a teacher/coordinator at the Adult Learning Program in Jamaica Plain.

Chaunda Scott, Interviewer. Chaunda will be completing her Ed.M focusing on Adult Education at the Harvard Graduate School of Education in December of 1997. She taught in community education and in ABE programs in the Minneapolis area for seven years. Besides being a graduate student, she is also a student research assistant for NCSALL. 


\section{What is the objective of the research?}

The study will present a comprehensive picture of the factors that work against or support the motivation of adult learners to persist in ABE programs. The study will focus on learners between a 5-8 ${ }^{\text {th }}$ grade reading level. Because of budget constraints we are focused on this population for our first study. We hope to do similar studies with other groups such as ESOL, 0-4 reading level, and GED.

\section{What research methods are being employed?}

- A review of the ABE Learner Motivation Literature

- One-on-one interviews with learners in Pre-GED classes across New England

\section{What kind of information is needed from adult learning centers?}

Interviews with learners will focus on what keeps learners motivated to stay in school. Questions are focused on identifying the various factors that work against and that support learners to persist in their programs. Some examples of possible factors are: family, friends, classmates, teachers, and classroom instruction.

To participate in the study, what kind of commitment does the learning center need to make?

- A one-hour class activity on motivation facilitated by members of the research team to introduce the participating class to the topic.

- 30 minute interviews with each learner both in the fall of 1997 and in the Spring of 1998. [note: if learners leave the program, we would still want to interview them if possible].

- An optional one hour follow-up session with the program to discuss the study's findings.

\section{How will the privacy of the learning center and of the learners be maintained?}

No one outside of the research team will have access to the true names of programs or of learners. For publication, all names will be changed. 


\section{How will the study's findings be used and disseminated?}

In general, the findings will be used to increase the knowledge that we, in the field of $\mathrm{ABE}$ have about the factors that work for and against learners as they strive to achieve their educational goals. They will be made available for teachers, counselors, program staff, and learners as data to reflect on and discuss as they continually make decisions about how they will carry out their program mission. The data will also be made available for program directors and policy makers to aid them as they advocate for more support for $\mathrm{ABE}$ programs. The next phase of this project will be the development of an intervention strategy meant to help learners identify the forces that help and hinder their participation, to build on the supporting forces, and overcome the forces that hinder their participation. That intervention will then be tested to assess its effectiveness.

\section{How will learners be compensated for their time?}

Each interview participant will be compensated $\$ 10.00$, paid after each $1 /$ hour interview.

******For further information, or to find out how your students can become involved in the study, please contact Andrea Parrella at NCSALL.

Ph: 617-495-1712 Fax: 617-495-4811. Email: Parrelan@HUGSE1.harvard.edu 


\section{APPENDIX B \\ ORIENTATION ACTIVITY WITH POTENTIAL INTERVIEW PARTICIPANTS}

\section{Set Up}

\section{A. chairs in semi-circle with big space in middle \\ B. with teacher, agree on days when we can interview learners}

I. Agenda: Research assistant and participants introduce themselves. Introduction: Thank you for working with us on the Learner Motivation Study. Today, we'll be doing a 30-45 minute activity to give you a better idea of what this project is about. Then we will answer any questions you may have about the project. Next week, we will do individual interviews with those of you who are interested.

\section{Motivation}

1. Ask participants: What are some examples of goals that people work toward in life? Write examples on newsprint. Choose one together to use for this activity (NB: if they name "GED" or "finishing school as a goal, then say, "I will be asking questions about that goal in the individual interviews. So for this activity, let's choose another goal")

2. Choose a goal and write it on the top of a piece of newsprint. [examples of goals chosen: renting an apartment, owning a home, getting off welfare]

3. Make a list together of who or what would help someone achieve this goal (supports/positive forces) and who or what would get in the way of achieving this goal (negative forces/obstacles)

4. Condense list: any repetitions? Comfortable with list?

5. Explain the role play and decide on roles: A person who is trying to reach $X$ goal has many supports and barriers. Let's say that the supports and barriers are voices inside the person's head, influencing her as she moves toward her goal. I'd like to ask for a volunteer who will play the role of this person trying to achieve her goal (goal from step \# 2). Then, I'd like the other participants to divide into two smaller groups: the supports and the barriers (the positives and the negatives). The "supports" go to one side of the table or room and the "barriers" go to the other side. The volunteer sits between both groups.

6. Ask the other participants to choose 1 support or 1 barrier from step \#3 and then spontaneously act out each force, going back and forth between 
supports and barriers, trying to build on what was said. Keep going until all the forces (or "voices") are heard. For example, a learner might say something like, "You can't rent an apartment. You don't have a steady job." And a positive force might respond with "I'm your friend and I'll help you think about ways that you can rent this apartment. We'll find a way." The participant who volunteered to be the one trying to reach the goal listens to all the forces as if they were voices within him or herself.

7. The research assistant explains that they are all acting out a role and that what they say does not necessarily represent their own views. They are to try to understand and bring to life the forces they have chosen and should feel free to add words and feeling to their role.

8. Once all the forces have been acted out, the teacher asks the volunteer what comments or reactions she might have and what she feels. The teacher gives this student the opportunity to speak first about her experience then asks the rest of the group what it was like to act out the forces.

9. Research assistant explains how this activity relates to the motivation study. Explanation: One of the main concerns in ABE centers is how to create an environment that will best work for you as students. Every day, you make a decision to come to school or not to come to school (point to 'buy the car' 'rent an apartment' and other side...). We would like to find out who or what the main forces are that convince you to come to school each day, and who or what are the main forces that may convince you not to come to school sometimes... and forces that may convince you to leave school. In the next week, we'd like to interview you individually to find out who or what these forces are in your lives. We plan to interview 220 students in New England in the next couple of months. In the Spring, we'd like to interview you again, to find out if the forces have changed. Then we'll put the information together and give it to teachers, program directors, you and other students [in a way that preserves privacy Ex: we'll say "20\% of students decide to stop coming to school because their pet iguanas are sick"]. You and other members of your learning center can use this information to think about ways to help increase the \# of students who reach their learning goals.

10. Research assistant explains how the interview questionnaire was created: We (research team)made a list (just like we did in this activity) of all the forces that we could think of(after reading articles by teachers, researchers, comments by students...) that work for and against students and them put 
them into categories(refer to the examples from the activity and explain categories...inside head/inside class/inside program/inside life). Then we wrote a set of questions to ask you about each category. [So for the example tonight, one category was and one example of a question might be The interview will take about 30 minutes to complete and will be conducted with during class time. (with teacher's permission). We hope that you'll be interested in interviewing with one of us. You are the experts of your own experiences and we're really interested in learning from you.

11. We are also able to pay you a small amount for your expertise (\$10-). You'll be compensated in cash right after the interview.

12. Answer any questions students have about the process. 


\section{APPENDIX C \\ ORIENTATION ACTIVITY WITH POTENTIAL INTERVIEW PARTICIPANTS (ONE ON ONE)}

I.

1. Ask participant: What are some examples of goals you might work toward/have worked toward in your life? Write examples on paper. Choose one together to use for this activity (NB: if they name "GED" or "finishing school as a goal, then say, "I will be asking questions about that goal in the individual interviews. So for this activity, let's choose another goal")

2. Choose a goal and write it on the top of a piece of paper. [examples of goals chosen: renting an apartment, owning a home, getting off welfare]

3. Make a list together of who or what would help someone achieve this goal (supports/positive forces) and who or what would get in the way of achieving this goal (negative forces/obstacles)

4. Condense list: any repetitions? Comfortable with list?

5. Discuss the supports and the obstacles. Which supports are the strongest? Which obstacles are the strongest? Which supports/obstacles can you change to help you reach this goal?

6. Research assistant explains how this activity relates to the motivation study.

Explanation: One of the main concerns in ABE centers is how to create an environment that will best work for you as students. Every day, you make a decision to come to school or not to come to school (point to 'buy the car' 'rent an apartment' and other side...). We would like to find out who or what the main forces are that convince you to come to school each day, and who or what are the main forces that may convince you not to come to school sometimes... and forces that may convince you to leave school. In the next week, we'd like to interview you individually to find out who or what these forces are in your lives. We plan to interview 220 students in New England in the next couple of months. In the Spring, we'd like to interview you again, to find out if the forces have changed. Then we'll put the information together and give it to teachers, program directors, you and other students [in a way that preserves privacy Ex: we'll say " $20 \%$ of students decide to stop coming to school because their pet iguanas are 
sick"]. You and other members of your learning center can use this information to think about ways to help increase the \# of students who reach their learning goals.

7. Research assistant explains how the interview questionnaire was created: We (research team)made a list (just like we did in this activity) of all the forces that we could think of(after reading articles by teachers, researchers, comments by students...) that work for and against students and them put them into categories(refer to the examples from the activity and explain categories...inside head/inside class/inside program/inside life). Then we wrote a set of questions to ask you about each category. [So for the example tonight, one category was and one example of a question might be The interview will take about 30 minutes to complete and will be conducted with during class time. (with teacher's permission). We hope that you'll be interested in interviewing with one of us. You are the experts of your own experiences and we're really interested in learning from you.

8. We are also able to pay you a small amount for your expertise(\$10-). You'll be compensated in cash right after the interview.

9. Answer any questions the student has about the process. 


\section{APPENDIX D \\ PROGRAM PARTICIPANT INTERVIEW GUIDE \\ LEARNER MOTIVATION STUDY \\ INTERVIEW PROTOCOL}

Thank you for participating in this study. I would like you to know that everything you say to me will be completely confidential. If you feel uncomfortable answering any question, let me know.

Do you have any questions? (pause) If you have any questions at any time or if you don't understand something I've said, please let me know.

\section{PART ONE}

I have five sets of general information questions I'd like to ask you before we talk about motivation. I apologize that there are so many, but hopefully we can get through these sections in 10 minutes or so.

\section{GENERAL INFORMATION}

In this first section, I'd like to get some general information about you.

1. How would you describe your race/ethnicity?

2. Could you tell me your age?

3. Do you have a job outside of your home? Yes No

4. How many hours per week do you usually work outside of the home including transportation?

5. Do you have children?
6. Are they living with you? Yes

7. What are their ages?

8. Are you a single parent?

Yes

No

\section{SCHOOLING}

For this second section, I'd like to ask you some questions about your schooling when you were a child.

1. What grade level were you in when you left school? 
2. What year did you leave school?

3. If you left school before graduation, why did you leave?

4. How would you rate your time in school?

$\begin{array}{ll}\text { very positive } & 5 \\ \text { positive } & 4 \\ \text { neutral } & \mathbf{3} \\ \text { negative } & \mathbf{2} \\ \text { very negative } & \mathbf{1}\end{array}$

5. Why?

6. When you did feel positive about school, what made you feel positive?

7. When you did feel negative about school, what made you feel negative? 


\section{INFLUENTIAL ADULTS IN YOUR LIFE}

This third set of questions is about the influential adults in your life when you were a child.

1. What adults played an influential part of your life when you were a child? (include those you lived with/those you didn't live with)

2. How many years of school did ___(answers to 1)__ complete?

(NB: number names in answer to 1)

3. What were __ (answers to 1)__ attitudes about school? 


\section{INFLUENTIAL PEOPLE IN YOUR LIFE CURRENTLY}

This fourth set of questions is about the influential people in your life now.

1. What adults play an influential role in your life (those you live with/don't live with)?

2. How many years of school did ___ (answers for \#1)__ complete? (NB: number names in answer to 1)

3. What are _ (answers for \#1)__ attitudes about school?

\section{PROGRAM EXPERIENCE}

This last set of questions before we start the section on motivation is about your experience with schooling as an adult.

1. How long have you been at ___ (name of current learning center)__ ?

2. Why did you decide to enter ___ (name of current learning center)__? 
3. Before you entered , did you ever do any self-study? (towards GED, or other academic goals) If yes, could you describe what you did?

4. Have you attended other ABE learning centers or other kinds of education programs?

[ Record information starting with the program the learner most recently attended.]

\section{\#1}

a. Where? (city,state)

b. When (year)?

c. How Long?

d. Day/Evening Classes?

e. Structured group/individualized?

f. Why did you decide to enter?

g. Why did you leave?

h. Was there any other reason why you left?

$\# 2$
a. Where? (city,state)
b. When (year)?
c. How Long?
d. Day/Evening Classes?
e. Structured group/individualized?
f. Why did you decide to enter?

g. Why did you leave?

h. Was there any other reason why you left?

\#3

a. Where? (city,state) 
b. When (year)?

c. How Long?

d. Day/Evening Classes?

e. Structured group/individualized?

f. Why did you decide to enter?

g. Why did you leave?

h. Was there any other reason why you left?

\section{PART 2}

Introduction: This next section of the interview will last for about 15 minutes. I'll be asking you questions about what helps you stay at __(name of learning center)__ and what causes you to think about leaving. Your answers will help to make changes at___name of learning center)__ and in other learning centers so they can better serve your needs. Please be as honest as you can. No one will be able to find out what you said.

Is there anything you'd like to ask me about before we continue?

\section{OPEN-ENDED QUESTIONS}

1. In general, how would you rate your time at __ (name of learning center)__?

$\begin{array}{ll}\text { very positive } & 5 \\ \text { positive } & 4 \\ \text { neutral } & 3 \\ \text { negative } & 2 \\ \text { very negative } & 1\end{array}$

2. When you do feel positive about your time at , what makes you feel positive? 
3. Do you ever feel negative about your time at ?

4. When you do feel negative about your time at what makes you feel negative?

5. Who or What is helping you stay in the program?

prompts 
6. Which is the most important, which is next, which is next? (put \#s next to \#5 answers) 
7. Who or What do you feel are obstacles to your coming to school?

prompts

8. Could you rate them? Which is the most important, which is next, which is next? (number answers \#7)

\section{SUMMATION}

1. One more time, of all we've talked about, who or what, in order of importance, help you the most to stay in school?

1.

2. 
3.

2. One more time, of all we've talked about, who or what, in order of importance, are the strongest obstacles to your coming to school ?

1.

2.

3.

3. Is there any thing else you would like to say?

4. What did you think of the Motivation Activity we did with your class? 
We would like to be able to contact you in about four months, even if you are no longer at__(name of learning center) We'd like your name, address and phone number and the name, address and phone number of someone who would know where you are if you move. Is this OK?

Interview participant\#

Name:

Address:

Phone \#

Contact:

Name of Learning Center:

City and State:

Name of Teacher:

Type of Class:

Here is my card. If you leave the program, I would appreciate you're giving me a call. You can call collect if you move to another state. Then I can interview you a second time over the phone. Also, if you think of anything that you'd like to add, please call. Thank you again, you were very patient. 
Fill This section out after Interview is Over

Interview Partner \#

Interview

12

Gender Male Female

Date

Class Time: Morning Afternoon Evening

Class Type: Structured Group Individualized

Amount of instruction time per week:

\section{CATEGORIES}

SELF

CLASSROOM

PROGRAM

LIFE (OUTSIDE OF LEARNING CENTER) 


\section{APPENDIX E}

\section{PERMISSION FORM}

Number:

Dear student:

Thank you for participating in the Adult Learner Motivation Study. Your name and all information from your interview will be kept completely confidential. By signing this form below you give your permission for your interview to be used in the study. At the end of the interview, you will be paid \$10-for your time and expertise.

Andrea Parrella, Ed.M.

NCSALL Research Assistant

I hereby give my permission for my interview to be used in the Adult Learner Motivation Study.

student's signature

Date

Please print:

Name:

Address:

Phone:

Social Security \#:

Contact name and phone: 